\title{
XXIV.
}

\section{Zur Histologie und zur systematischen Stellung der schleimigen oder gallertigen Gewebe des Menschen.}

\author{
Von Dr. G. Kickhefel, \\ Volontair-Assistenten am pahologischen Inșitut zu Greifswaic.
}

(Hierzu Taf. XVI-XVII.)

Die Entdeckung von P. Grawitz über das Vorkommen siner Umwandlung von faseriger und homogener Grundsubstanz in Kerne and Zellen hat die Anregung zu einer Reihe von Arbeiten gegeben, welche die Richtigkeit der neuen Lehre am Bindegewebe, der serösen Häute, am elastischen Gewebe der Arterien, an der Hornhaut, dem Fettgewebe, dem Knorpel und den Muskeln bestätigt haben. Ein Ueberblick, soweit ein solcher zur Zeit möglich ist, lässt uns überall den engen Zusammenhang erkennen, welcher zwischen der embryonalen Gewebsbildung, zwischen dem Ausreifen jugendlicher Gewebe, zwischen der physiologischen Altersinvolution einerseits und den pathologischen Gewebsveränderungen andererseits in weit höherem Grade, als man vorher vermuthen durfte, vorhanden ist. Die verschiedenen fertigen normalen Gewebe sind aus einem ursprünglich rein zelligen Zustande hervorgegangen, sic haben eine jugendliche Periode durchgemacht, in welcher neben Zellen bereits Grundsubstanz oder Zellenverbände mit höher differenzirten Bestandtheilen (Myosin, Myelin u. s. w.) vorhanden sind, und sie sind erst dadurch zur vollendeten Ausbildung gekommen, dass mehr und mehr die Bildungszellen und ihre Kerne in den Schlummerzustand übergegangen sind.

Bei Ernährungsstörungen sind wir seit Virchow gewohnt, gewissermaassen eine strenge Grenze zu ziehen zwischen progressiven und regressiven Prozessen, denen sich die gemischten anschliessen, bei denen auf den progressiven Anfang ein regressives Endstadium folgt. Wir können jetzt sagen, dass alle Er- 
Virchow's Archin BC.CXXXX.

Taf $X V Z$

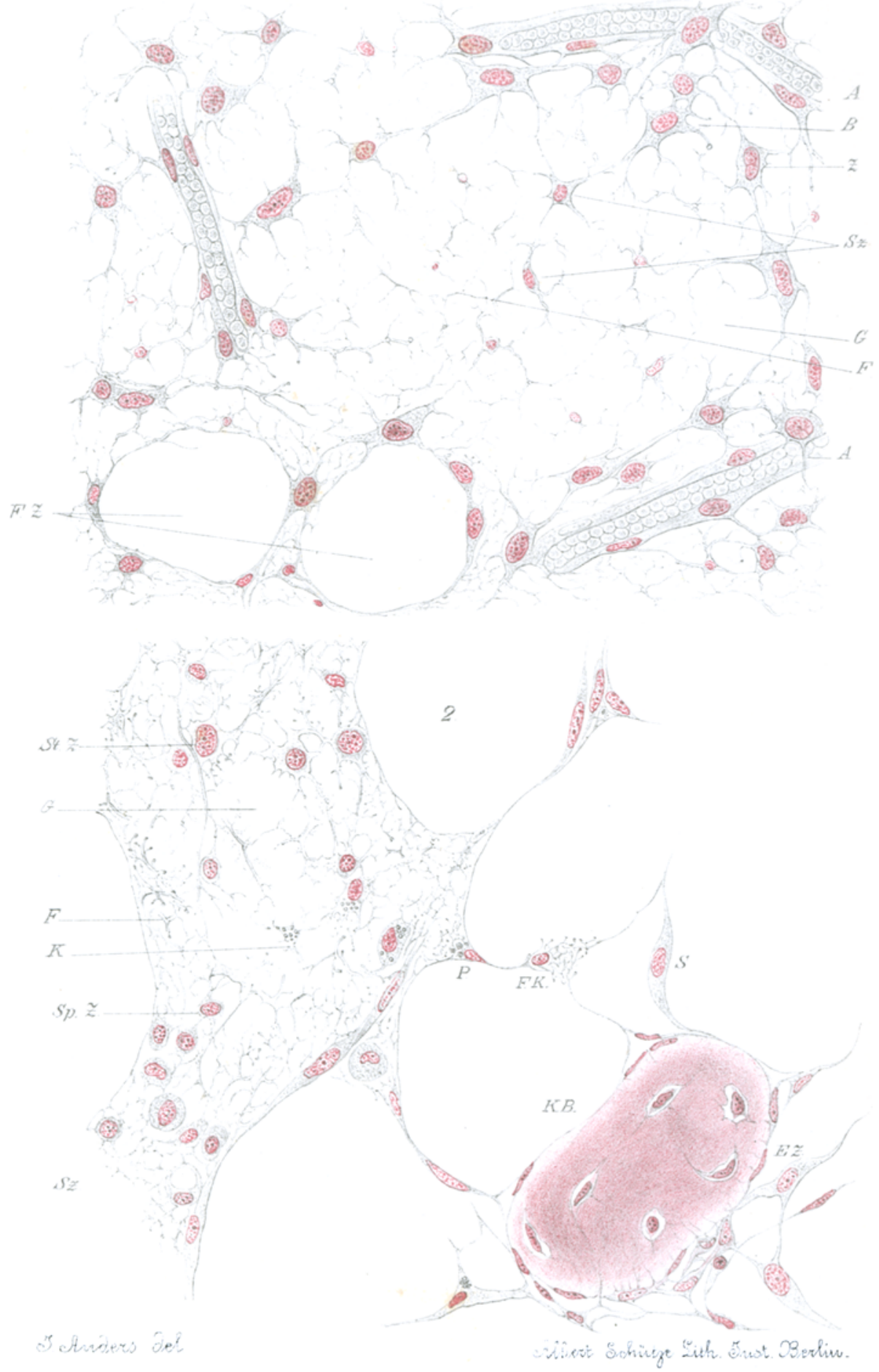


3.
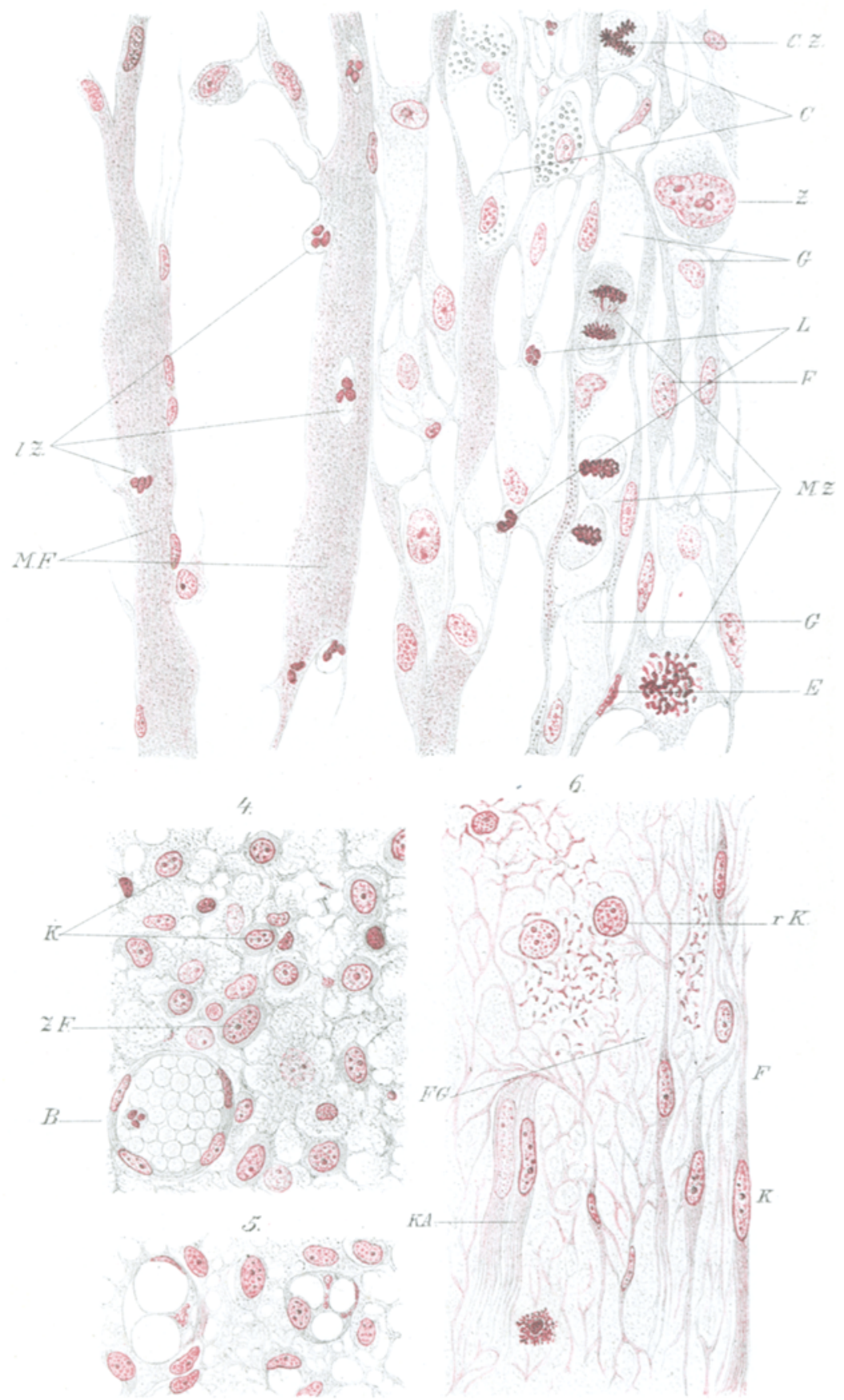
nährungsstörungen, also alle pathologischen Gewebsveränderungen, welche nicht direct der Nekrose angehören, einen Rückgang zu den Perioden einer früheren Entwickelung bilden, welches bald nur wenige Schritte rückwärts in die Jugendzustände, bald bis zu dem rein zelligen Zustande der frühesten Embryonalperiode zurückführt. Je nachdem nun dieses Erwachen zu Jugendformen länger oder kürzer anhält, je nachdem daraus endlicher Untergang oder baldige Wiederherstellung der normalen Entwickelungshöhe wird, nennen wir die Prozesse: Atrophie, Entzündung, Regeneration u. s. w. Namentlich die Entzündung ist kein absolut eigenartiger rein pathologischer $V_{\text {organg, wie ihn }}$ die Emigrationslehre erscheinen liess, sondern sie steht in gleicher Reihe mit den oben beschriebenen Prozessen, sie ist sowohl in ibrem acuten Ablaufe als auch unter der Erscheinungsform einer chronischen Wucherung in den Bindesubstanzen sowie im Muskel- und Nervengewebe immer zuvörderst ein Rückgang $\mathrm{za}$ einer Struktur, welche das betroffene Gewebe in einer früheren Zeit vor vollendeter Entwickelung einmal durchlaufen hat ${ }^{1}$ ).

Wenn sich in einem reifen Gewebe eine Geschwulst entwickelt, so wissen wir durch Virchow, dass häufig die Anfänge derselben durchaus den Gewebsveränderungen bei der Entzündung gleichen. Die neugebildete Geschwulst erreicht später entweder den Bau des Muttergewebes oder doch einer Vorstufe desselben (Homologie) oder von dem zelligen Jugendstadium aus entwickeln sich vollendete Gewebsformen einer anderen Art (Heterologie), oder beide Vorgänge laufen neben einander her, alsdann entstehen die Mischgeschwülste. Zwischen den fertigen homologen histioiden Tumoren und den unfertigen, überwiegend zelligen, Sarcomen stehen als $\mathrm{Zwischenstufen} \mathrm{oft} \mathrm{Gewächse} \mathrm{von}$ schleimiger oder gallertiger Beschaffenheit, so dass Virchow sich genöthig $s a h$, in die Reibe der Bindesubstanzen ein Schleimgewebe (Tela mucosa) einzuführen, obgleich dasselbe unter den

1) S. den Vortrag von P. Grawitz auf dem Chirurgencongress 1892: „Ueber die Gewebsveränderungen bei der Entzündung und ihre biologische Bedeutung." Siehe S. Stricker, Lehrb. d. Pathol. 1883, welches S. 830 die Umwandlung von Protoplasma der Zellen und Fasern an der Froschcornea beschreibt, und daraus das gleiche Princip herleitet, welches P. Grawitz aus seinen Beobachtungen gewonnen hat. 
reifen Körpergeweben des Nenschen nicht vertrecen ist, sondern sich aus ihnen nur unter pathologischen Verhältnissen entwickelt.

Virchow bezeichnet das Schleimgewebe als die Vorstufe und unter Cmständen als die Degenerationsstufe zweier verschiedener definitiver Gewebe, nehmlich des Fet- und Bindegewebes, und ausserdem lässt er auch noch andere Glieder der Bindesubstanzen, z. B. das Knochenmark in das Schleimgewebe sich umwandeln. Hiermit ist offenbar das Schleingewebe zu einem indifferenten Gewebe gestempelt, man darf es als oine Vorstufe betrachten, welche sehr mannichfachen Gewebsarten gemeinsam ist.

Diese Auffassung hat wohl dazu geführt, dass in der Literatur das mesodermale Schleimgewebe so häufig als embryonales bezeichnet wird, wobei der Gedanke zu Grunde liegt, dass sich dasselbe bald zu dem einen bald zu dem anderen Gewebe differenziren könnte. Nun habe ich aber Eingangs dieser Abhandlung bereits erwähnt, dass die verschiedenen Gewebe bei allen Ernährungsstörungen in ein gewissermaassen embryonales Stadium zurückgebildet werden, ja dass sie beim Heilungs- und Eutzündungsvorgange sogar in den frühesten rein zelligen $\mathrm{Zu}$ stand zurückgehen, ohne dass man denselben deswegen als indifferent bezeichnen könnte, da sich in jedem Organ doch imwer wieder dasjenige Gewebe daraus aufbaut, welches an Ort und Stelle das normale ist, wenn dieses auch, wie beim Fettund Muskelgewebe auf Umwegen erfolgt.

Ich habe mir darum zur Aufgabe gemacht, das Schleimgewebe, den Jugendzustand des Fettgewebes und anderer Bindesubstanzen, das Schleimgewebe als Involutionszustand von Fettund Knochenmark, das Schleimgewebe in homologen und heterologen Tumoren zu untersuchen, um festzustellen, ob das Schleimgewebe überhaupt eine besondere Gewebsart ist, und falls sie os ist, ob es eine indifferente Vorstufe vieler Gewebe ist, oder welcher Rang ihm unter den übrigen Geweben zukommt.

Virchow war der erste, der das Schleimgewebe einer genaueren Untersuchung unterwarf, er fand, dass ,sich in den Maschen eines areolären Gewebes Schleim befindet, der sich in glatte, in Essigsäure unlösliche sternförmig verästelte und am Ende in Fasen zersplitternde, in der Mitte mit einer in Essig- 
säure erblassenden und häufig mit einigen Fettmolecülen umlagerten Kerne versehene Elemente zerreissen lässt." Ausser dem Schleim, der sich chemischen Reagentien gegenüber so verhält, dass er einen durch Alkohol in Fäden fällbaren und in Wasser wieder aufquellenden, durch Essigsäure fällbaren und im Ueberschuss sich nicht lösenden Stoff, das Mucin, enthält, und der streifigen kernhaltigen Maschensubstanz fand er noch runde granulirte kernhaltige Zellen mit gegen Wasser, Essigsäure u. s. w. resistenter Membran aus zähem gerinnendem und zusammenschrumpfendem Inhalt. Nach diesem Schleim der den Hauptbestandtheil des Gewebes bildet und dem Gewebe die eigenthümliche gallertige Beschaffenheit verleiht, behielt Virchow den schon früher von Bordeu gewählten Ausdruck Tissu muqueux bei und nannte dies Gewebe Schleimgewebe. Er erklärte es sich genetisch so, dass die Zellen das Primäre seien, der Schleim dagegen erst secundär durch active Thätigkeit der Zellen entstehe, und nur ein Abscheidungsprodukt derselben sei. . In die Gruppe des Schleimgewebes rechnete er den Nabelstrang, die sogenannte Wharton'sche Sulze, ferner den Glaskörper des Auges, ganz besonders das Schleimgewebe bei jüngeren Embryonen an Stellen, wo sich später fibrilläres Bindegewebe oder Fettgewebe bildet, wo es also als Vorstufe dieser Gewebe aufzufassen ist. Da es sich nun um unfertiges Bindegewebe, d. h. um Bindegewebe in dem frühesten Stadium der Entwickelung handelte, so musste sich dementsprechend dieses Gallertgewebe bei niederen Thieren, zumal bei Wirbellosen sehr verbreitet vorfinden, und so kam es, dass eine Anzahl von Untersuchungen über das Schleimgewebe hauptsächlich an niederen Thieren, besonders solchen aus der Klasse der Mollusken gemacht worden sind ${ }^{1}$ ). Alle diese Untersuchungen be-

1) In seiner Arbeit "Histiologische Studien über die Kiemen der acephalen Mollusken" (Archiv f. mikroskop. Anatom. Bd. XIV.) findet sich von C. Posner die damals schwebende Streitfrage über das Gallertgewebe behandelt, bei welcher Posner sich am meisten dem Standpunkt von Max Schultze anschliesst, dessen Anschauung Posner in die folgenden Sätze fasst: „das Zellprotoplasma ist das allein lebende im Gewebe, die Intercellularsubstanz, ihr Produkt und Derivat, ist für sich allein todt, physiologischer Acte unfähig und wird, so lange die Zelle lebt, von ihr beherrscht". Unzweifelhaft am meisten nähert sich 
staxtigen im Grossen uad Ganzeu nul das, was Fichow schon als charakteristiseh für das Schleimgewebe aufgestellt hat; wenngleich auch Differenzen in der Bezeichnung vorkamen, so war doch die Auffassung von dem histologischen Bau dieselbe. So wählte z. B. Kölliker die Bezeichnung "netzförmiges oder gallertiges Bindegewebe", indem er diesen Namen wegen der anastomosirenden sternförmigen Zellen einführte. Er fasst das Schleimgewebe auf als ein nicht vollkommen ausgebildetes junges oder auch wohl älteres unreifes Bindegewebe, als ein Entwickelungsstadium von Bindegewebe, welches nicht zur vollen Ausbildung gelommen ist, das bald arm, bald reich an Zellen und elastischen Fasern ist und eine gallertige Beschaffenheit angenommen hat, wie embryonales lockeres Bindegewebe, und in den Maschen der Bindegewebsbündel eine bald mehr serumartige bald schleimund eiweisshaltige Flüssigkeit enthält.

Mit dem Grade, wie sich die Lehre vom Bindegewebe, der feineren Structur desselben weiter ausbildete, trat die Vorstellung von dem homogenen schleimigen Wesen des Schleimgewebes in den Hintergrund, man betrachtete die weichen Bindegewebsmassen meist nur als blosse Abart, wie neuerdings Stöhr u. A. es thun.

Nachdem lange Jahre die von Virchow gemachte Darstel. lung von pathologischer Seite angenommen war, erhob Köster dagegen Einspruch, indem er die Auffassung des Schleingewebes als jugendliches Bindegewebe oder Fettgewebe bestreitet. Nach seiner Ansicht ist das Schleimgewebe völlig identisch mit lockerem oder aufgequollenem Bindegewebe, der Mucingehalt ist in dem Schleimgewebe kein grösserer als im Bindegewebe, das Mucin ist nur durch Serum sehr stark aufgequollen, es handelt sich beim Schleimgewebe nur um ödematöses Bindeoder Fettgewebe; im letzteren verlieren die Zellen ihr Fett

den von uns vertretenen Anschaunngen über das Leben und die Rückbildungsfähigkeit der Gruadsubstanz Si g m. Mayer (Arch. f. Psychiatrie 1875), welche aus Fasern nicht nur wieder Fasern, sondern auch Zellen und freje Kerne hervorgehen lässt. Ueber die Entstebung der Gefässe und die Abbängigkeit der Zellen von der Grundsubstanz sowie deren chemische Beschaffenheit finden sich bei Posner eingehende Erörterungen, anf welche wir im engen Rabmen dieser Arbeit nur binweisen wollen, da unsere Auffassung mit keiner der früheren sich gänzlich deckt. 
und bleiben als protoplasmatische Bindegewebszellen zurück. Die Ursache für die Entstehung des Schleimgewebes findet Köster in Circulationsstörungen, indem Capillaren und Venen fast immer erweitert und gefüllt sind, ihm ist Myxomgewebe und Oedem vollständig identisch nur mit dem Unterschied, dass die jungen Gefässe der Geschwülste eine grössere Permeabilität für flüssige Bestandtheile des Blutes haben können; die Myxome sind weiter nichts als Fibrome oder Lipome, die durch irgend welche Circulationsverhältnisse ödematös geworden sind.

Zur Prüfung der vielen Streitfragen lasse ich nun zunächst meine Beobachtungen folgen. Meine Darstellung soll mit der Beschreibung derjenigen unfertigen embryonalen oder jugendlichen Gewebe beginnen, welche R. Virchow bei der Begründung der Lehre vom Schleimgewebe als die Typen desselben aufgestellt hat, nehmlich mit Nabelstrang (Fall 1 u. 2) und dem Unterhautgewebe vor der Ausbildung von Fettgewebe in demselben (Fall 3. 4).

Es folgt darauf ein Kapitel über die gleichsam physiologische Rückbildung des Fettgewebes in Schleimgewebe, wie sie im hohen Alter vorkommt. Ganz ähnliche Umbildungen können auch in Folge verschiedenartiger allgemeiner oder localer Ernährungsstörungen als unzweifelhaft pathologische Vorgänge auftreten; ich habe darüber 3 Fälle mitgetheilt, die ersten beiden (Fall. 5. 6) betreffen das Fett im Nierenhilus, welches in Fall 5 wegen allgemeiner Ernährungsstörung in einfaches Schleimgewebe umgebildet ist, im 6 . Falle durch entzündliche Reizungen in eine geschwulstartige Wucherung übergegangen ist. Die Beobachtung (Fall 7) von pathologischer Umwandlung von Fett in Schleimgewebe ist durch locale Entzündung bedingt.

Ich gebe alsdann Beispiele vom Uebergang von Bindegewebe in Schleimgewebe (Fall 8.9 und Fall 10), vom Uebergang des Knochenmarkes in Schleimgewebe (Fall 11), vom Uebergang des peripherischen Nervengewebes in Schleimgewebe (Fall 12) und des centralen in Gliombildung (Fall 13). Alsdann folgt an Beispielen ein Vergleich der Tela muscosa mit ödematösem Fettund Bindegewebe. Den Schluss bilden die Tumoren, die vorwiegend Schleimgewebe enthalten (Myxome, Myxolipome, Myxosarcome, Gallertcarcinome). 


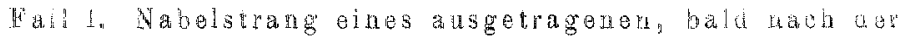
Geburt gestorbenen Nelgebornex.

Die Untersuehung des frischen Objectes ergiebt in einer howogenen Gruaưsubstanz schöne grosse spindelige oder sternförmige Zellen mit langen Ausläufern, die rielfach unter einander anastomosiren; nach Essigoäurezusatz zeigt die Intercellularsubstanz eine deatliche Mucinreaction und in den Zellen treten schöne bläschenförmige Kerne mit einem oder mehreren Kerbkörperchen hervor. Bei der Untersuchung von gebärteten und gefärbten Schnitten bei schwacher Vergrösserung (30mal) sieht man ein einfaches Bild; in einer schwach rosa gefärbten, vielfach Spalten und Fücken enthaltenden, homogen erscheinenden Intercellularsubstanz liegen als intensiv rotb gefürbte Punkte erkennbare Zellen, die mit Jangen Ausläufern mit einander anastomosiren und vielfach in Reihen angeordnet sind, so dass thre Anordnung an die der Knochenkörperchen erinnert. Bei Betrachtung mit stärkster Vergrösserung (0el-Imm. $\frac{1}{12}$ Oc. 2 ) sind die Zelleiber schwach grauroth gefärbt und enthalten einen feingranulirten meist länglich gestreckten roth gefärbten Kern mit scharf hervortretender Kernmembran und Kernkörperchen; die Zellen sind entweder prachtvolle grosse mit einander anastomosirende Sternund Spindelzellen, deren Ausläufer sich als scharfe Fäden deutlich ron einer Zelle zur anderen verfolgen lassen, oder mehr rundlich geformte Zellgebilde mit gleichfalls feingranulirtem länglichem Kera. Alle Zellen haben in dem vorliegenden Präparat noch die Eigenthümlichkeit, dass ibre Kerne umlagert sind von feinsten Fettröpfchen, welche durch die Einwirkung der Flemmingschen Lösung als kleine intensiv schwarz gefärbte Kügelchen bervortreten. Neben diesen vollständig erhaltenen Zellen finden sich nun alle Abstufungen des Uebergangs in die Schlummerform. Zunächst trifft man Zellen, welche den Eindruck machen, als ob auf den Zelleib die Farbflüssigkeit nicht genügend eingewirkt hätte, wäbrend die Kerne noch deutlich gefärbt sind; diese Zellleiber können schliesslich so schwach gefärbt werden, dass man oine Tremnung des Zellprotoplasmas von der umgebenden Intercellularsubstanz nicht mobr machen kann, nur die um den alscann frei erscheinenden Kern sich lagenden Fettropfen deuten auf einen früber vorbanden gewesenen Zelleib hin. Diese freien Keme blassen ab und verschwinden schliesslich ganz, so dass endlich nur noch die kleinen Fetttröpfeben anzeigen, dass früher hier eine vollständig intacte Zelle ibre Lage gehabt hat. Die Fetttropfen sind, wenn sie in grösserer Anzahl vorhanden sind, meist so gelagert, dass sie entweder sternförmige oder spindelige Figuren bilden, wodurch dann noch die Form der früheren Zelle angedeutet wird.

Was nun die Intercellularsubstanz betrifft, so zeigt dieselbe im Durchschnitt feinfasrige Structur, die feinen grauroth gefärbten gerade noch als solche erkennbaren Fasern sind vielfach verschlungen und wellig anfgerollt. Diese Intercellularsubstanz ist nun unterbrochen von einem Kanalwerk, das sowohl in Form von Spalten als in Form von Lücken auftritt; der grösste Theil dieses Kanalsystems ist jedenfalls künstlich durch den Druck des Deck- 
glases entstanden. In der Wand dieser Lücken und Spatten finden sich an zahIreichen Stellen dieselben Iänglichen feingranulirten Kerne, wie sie oben bei den anastomosirenden Gewebszellen beschrieben sind; das zu den Kernen gebörige Zellprotoplasma fehlt meist, dagegen kann man noch vielfach einen Zusammenhang von 2 wei benachbarten an der Wand einer Spalte liegenden Kernen erkennen durch eine feine als feinste Faser auftretende Anastomose. An vielen Spaiten fehlen diese Kerne gänzlich, nur von Strecke zu Strecke treten in der Wand Complexe von feinsten Fettröpfchen auf.

Epikrise: Die Zellen des vorliegenden Gewebes zeigen denselben histologischen Bau, wie ihn Virchow für das Schleimgewebe beschrieben hat, schöne, theils spindelförmige theils sternförmige kernhaltige zuweilen mehrkernige granulirte Zellen, welche durch lange Ausläufer mit einander anastomosiren; diese Zellen sind als die permanenten Zellen des Nabelstranges aufzufassen. Wie es aber im Bindegewebe neben den permanenten Zellen solche giebt, welche sowohl in als an den Faserbündeln liegen, und die Intercellularsubstanz bilden, so geht auch hier ein anderer Theil der Zellen, welche vielfach in Reihen angeordnet sind, in Intercellularsubstanz über; dabei erleichtern die sich um die Kerne gruppirenden Fetttröpfchen es bedeutend, alle Stadien der Umwandlung von Anfang bis zum Schluss zu verfolgen. Es formt sich zunächst das Zellprotoplasma in Intercellularsubstanz um, es liegen dann freie Kerne in einem Hof von feinkörniger Zwischensubstanz, darauf betheiligen sich auch die Kerne an dem Umwandlungsprozess, sie blassen ab, lösen sich auf, nur die Fetttröpfchen bleiben bestehen, und zeigen an, dass früher an Stelle der feinkörnigen Intercellularsubstanz eine Zelle gelagert hat. Weiterhin helfen die Zellen am Aufbau der Saftspalten, indem sich zunächst der Zellleib zu einem Saftkanal umformt und der Kern zunächst noch bestehen bleibt, bis allmählich auch dieser mehr und mehr abblasst.

Die histologische Beschaffenheit des Nabelstranges stimmt also vollständig überein mit der Virchow'schen Auffassung, nur in Bezug auf die Genese der Intercellularsubstanz kann ich der Virchow'schen Ansicht nicht beitreten. Während Virchow sich die Grundsubstanz als ein Abscheidungsprodukt der Zellen denkt, beweist das vorliegende Präparat auf das klarste, dass die Intercellularsubstanz selbst zellig, und durch Umwandlung der Zellen entstanden ist. Die Zellen wandeln sich einerseits 
in Grundsubstanz um, nach der Bildung derselben rerwandelt sich ein anderer Theil der Zellen in die die Grundsubstanz durchziehenden Saftspalten, in denen Gewebsfiussigkeit circulirt, die dem Gewebe die eigenthümliche geléartige Beschafenheit verleiht.

Fall 2. Nabelstrang eines sechsmonatichen Embryo.

Bei der Untersuchung des frischen Präparats, das wit einer wässrigen Methylenblaulösung schwach gefärbt ist, findet sich eine feinkömige Intersellularsubstanz, die von langen feinsten Fasera nach allen Richtungen durcbzogen ist, daneben finden sich längliche Kerne.

Bei schwacher Vergrösserung bietet ein gefärbter Scbnitt dieselbe histologische Struktur wie im vorigen Präparat, nor ist die Anordnung der Zellon in versehiedenen Theilen des Präparates eine verschiedene, ebenso wechselt ibre Form nach der Entfernung von dee Gefässon. In unmittelbarer Nähe der Gefässe ist nehmlich die Anordnung der Kerne eine bedeutend dichtere als in den entfernten Bezirken. Die Kerne haben in der Nahe der Gefässe eine mehr rundliche Form, sie liegen auch zwischen den äusseren Lagen der Gefässwand selbst, so dass in den äusseren Partien der Gefässwand ringförmige Jagen von runden Kernen mit ringförnigen parallelen Lagen von spindelförmigen Zellen oft abwechseln. Je weiter man sich vor den Gefässen entfernt, um so spärlicher werden die Zellen und um so mehr tritt die Intercellularsubstanz in den Vordergruad. Nahe der Oberfäche des Nabelstranges anastomosiren die Zellen durch lange Ausläufer, die in Zügen parallel zar Oberflacke angeordnet sind, so dass dadurch eine gewisse lamellöse Struktur ontsteht. Die Oberfäche des Nabelstranges ist von oiner Epithellage bedeckt. Um bei der Untersuchung mit stärisster Vergrősserung auch dort anznfangen, wo genetisch der Anfang der Schleimgewebsentwickelung zu suchen ist, wird zunächst die Gefässwand einer Untersuchung unterworfen. Die Wand besteht aus einer Anzahl concentrischer Lagen von schöner Spindelzellen mit einem ovalen Kern vom Typus der Bindegewebskerne. Diese Spindelzellen liegen in den innersten Lagen des Gefässes concentrisch neben einander, werden aber in den änssersten Theilen der Wand von runden Zellen mit bellem durchscheinendem Leib und einem gekerbten leukocytenähnlichen Kern unterbrochen, indem sich diese runden Zellen zwischen die äussersten Lagen der Zellen der Gefăsswand eindrängen. Beide Zellsorten betheiligen sich nun an dem Aufbau des Gewebes. Einmal bieten die Spindelzellen in den äussersten Lagen alle Stufen der Umwandlung in Intercellularsubstanz dar, so dass der Gang der Umwandlung derselbe ist, wie im ersten Falle beschrieben. Einen grösseren Antheil am Aufbau der Intercellularsubstanz wie die Spindelzellen haben die leukoeytenähnlichen Zellen; der Gang ist auch bier derselbe wie im vorigen Präparat. Je mehr man sich von den Gefässen entfernt, um so spärlicher werden die Kerne, in der Peripherie finden sich Lagen von grossen spindelförmigen Zellen mit langen Ausläufern, die mit einander anastomosiren. Diese Spindelzellen laufen parallel der 
Oberfläche, und bilden so concentrische Lagen, zwischen denen sich aber immer noch eine feinfasrige Intercellularsubstanz findet. Auch in dieser Intercellularsubstanz trifft man alle Uebergangsformen in den Schlummerzustand an den leukocytenähnlichen Zellen.

Epikrise: Dieses vorliegende Gewebe stellt uns ein früheres Stadium der Entwickelung des Nabelstranges dar: während im ersten Falle sich durch das ganze Präparat verbreitet eine meist feinfaserige Grundsubstanz mit langen anastomosirenden Spindelzellen fand, wodurch sich das Gewebe dem fibrillären Bau des Bindegewebes nähert, trifft man hier dieselben nur in den ältesten Theilen, in der Peripherie, wo sie zu concentrischen Lagen angeordnet sind, und eine lamellöse Anordnung zeigen, wie man sie bei Knochenschliffen an den concentrischen Lagen um die Havers'schen Kanäle beobachtet. Je mehr man sich den Gefässen nähert, um so zellenreicher und um so jünger wird das Gewebe. In unmittelbarer Nähe der Gefässe finden sich fast nur Zellen bezw. Kerne, so dicht, dass sie fast keine Intercellularsubstanz zwischen sich lassen; hier ist der Anfang der Bildung des Schleimgewebes zu suchen. Der durch die Gefässe strömende Blutstrom giebt den Zellen der Gefässwand genügend Ernährungsmaterial, sie vermehren sich und die Gefässwand scheint dann nur aus neben einander liegenden Zellen zu bestehen. Die Zellen der äussersten Lagen bilden sich zunächst in das Schleimgewebe um, Schritt für Schritt ist dabei die Umwandlung der Zellen in Intercellularsubstanz zu verfolgen. Die fertig gebildete Grundsubstanz ist deshalb verhältnissmässig arm an Zellen, die wenigen vorhandenen Zellen sind als die permanenten Zellen aufzufassen, die dann, je älter das Gewebe wird, in Anastomose treten, wie hier in den peripherischen Theilen, und schliesslich das Endstadium der Entwickelung darstellen.

Auffallend ist, und das möchte ich hier betonen, dass bei dem älteren Nabelstrang die Grundsubstanz entschieden eine mehr faserige Struktur hat, was sich besonders zeigt, wenn man zwei Schnitte aus beiden Fällen neben einander betrachtet. Es deutet uns dies schon an, dass in diesen beiden Fällen das Schleimgewebe einen fibrösen Zustand darstellt, der immer deutlicher wird, je älter das Gewebe des Nabelstranges wird, so dass das Schleimgewebe hier als Aequivalent des Bindegewebes aufzufassen ist. 
Fall 3. Subcutanes Schleingewebe aus der Planta pedis eines viermonatiohen Eubryo.

Zum Zweke der Untersuchung des Unterbautgewebes weldem zon einem viemonalichen Fmbryo Stücke aus der Planta pedis exstirpirt, in Alisohol gehärtet und mit Saffranin gefärbt. Bei schwacher Vergrösserung sieht man zunächst als scharfe, intensiv roth gefärbte Linie die Epithellage der Haut, die sich rom Unterbautgewebe scharf abhebt, mehr nach der Oberfläche him blasser wixd; in dieser Epithellage liegen als rothe Pünktchen erkennbare runde Kerne. Von dieser Epithellage senken sich an einigen Stellen. kloine Epitheleinstülpungen in die Tiefe. duf diese folgt eine ungefähr zehnmal so dicke, sebwach rosaroth gefärbte Lage des Unterbautgewebes; in diesen Bezirk sind Blutgefässe, von denen einige in ihrem lumen noch rothe Blutkörperchen enthalten. In der homogen erscheinenden Intercellularsubstanz liegen zahlreiche Kerne, theils in Gruppen angeordnet, theils durch das ganze Bild zerstreut. Auf diese Lage folgt eine Knorpellage, die den Fusswurzelknochen angehört. In einer hyalinen Zwisebensubstanz liegen meist als spindelförnige rothe Figuren exkenubare Knorpelzellen.

Es interessirt für die vorliegende Untersuchung nur die mittelste Lage der Unterhaut; bei der Betrachtung mit stärkster Vergrösserung zeigen sich zunächst die oben bezeichneten Zellen als Zellikeme, die fein granulirt, roth gefürbt sind, und meist dentlich Kernmembranen und Kernkörperchen erlennen lassen. Die Zellkerne sind entweder runde Gebilde von der Grösse der rothen Blutkörperchen oder sind mebr länglich und oval und ähneln dalurch den Kernen der Endothelien. Die runden Keme lassen in der bei Weitem grössten Mehrzabl einen Zelleib nicht mehr erkennen, nur hier und da ist ter runde Kern von einem schmalen, hellen, durchscheinenden, farblosen Saum umgeben, der sich von der schwach rosa gefärbten Intercellularsubstanz scharf abhebt. Diese runden Kerne geben nun allmählich in die Schlummerform über, der Kern löst sich dabei in mehrere Kerabröckel aur, wird immer blasser, bis er schliesslich ganz verschwindet und man vielleicht höchstens noch einen ganz schwachen rosigen Schimmer in der feinkörnigen Intercellularsubstanz wahrnimmt. Die andere Form der Zellkerne, die länglichen ovalen, lässt meist den Zellleib deutlich als feine Ausläufer an den Polen erkennen, so dass dann eine schöne Spindelzelle entsteht. Gelegentlich anastomosiren zwei solche spindelförmigen Zellen durch ihre Auslaufer, so dass man den Eindruck einer Faser erhält, in deren Verlauf Kerne eingeschaltet sind. Diese anfangs soliden Fasern formen sich allmäblich zu feinen Röhren und Spaiten um, zwei solche Zellen mit länglichen Kernen sind in Verbindung getreten, in der Nähe der Zellen sind die Fasern schon bohl, in der Mitte zwischen den Zellen nocb solide; an anderen ist auch der mittlere Theil bohl, wan erbält Saftspalten mit wandständigen Kernen. Sehliesslich können auch die Kerne an diesen Saftspalten in den Schlummerzustand übergehen, es bleiben dann einfache Röhren mit kernlosen Wandungen übrig. 
Die Intercellularsubstanz ist in diesem Fall feinkörnig, schwach rosa gefärbt, an manchen Stellen tritt diese feine Körnung mehr in den Hintergrund und macht einer mehr feinfasrigen Struetur Platz; in den letzteren Bezirken finden sich auch meist die Saftspalten in grösserer Anzahl.

Epikrise: Bei dem Unterhautgewebe dieser 4 monatlichen Frucht findet sich noch nirgends eine Andeutung einer Fettgewebsbildung, sondern das ganze subcutane Gewebe bietet die histologische Beschaffenheit des Schleimgewebes, wie es als Vorläufer des subcutanen Fettgewebes von Virchow beschrieben und als solches auch als unfertiges Fettgewebe bezeichnet ist. Die Gewebszellen bieten hier zwar nicht den Typus der grossen schönen anastomosirenden granulirten Zellen, wie sie beispielsweise im Nabelstrang angetroffen werden, sondern zeigen noch jugendliche Formen; diese Gewebszellen bilden sich nun einmal zu Intercellularsubstanz um, und zwar betheiligen sich an diesem Prozess wesentlich die runden Formen; die Intercellularsubstanz ist also auch hier zelliger Natur, nicht Abscheidungsprodukt der Zellen. Die andere Art der Zellen mit spindelförmiger Gestalt betheiligen sich an dem Aufbau der Intercellularsubstanz nur so weit, als sie sich zu Saftspalten und SaftkanäIchen umformen, haben sie diesen Prozess durchgemacht, so gehen auch sie in den Schlummerzustand über, die Saftkanälchen werden kernlos. Also auch die Saftkanälchen bestehen aus lauter Zellen, die aber als solche nicht sichtbar sind, sondern schlummern, d. h. sich in einer Modification befinden, in welcher die Molecüle nicht in Form und chemischer Zusammensetzung von Kernsubstanz (Chromatinsubstanz) und Zellenprotoplasma gelagert sind.

Fall 4. Subcutanes Schleimgewebe an der Planta pedis eines sechsmonatlichen Embryo (Fig. 5).

Einen weiter vorgeschrittenen Grad der Entwickelung zeigt das Unterhautgewebe eines 6 monatlichen Embryo; die Stücke werden aus derselben Gegend entnommen und ebenso vorbereitet.

Bei der Betrachtung mit schwacher Vergrösserung erkennt man ebenfalls die Epithellage der Epidermis, unter dieser folgt zunächst eine Sebicht, welche ziemlich gleichmässig gefärbt ist und eine gleichmässige Anordnung der als rothe Pünktchen erkennbaren Kerne zeigt. Diese Lage, die eine ungefähr zebnfache Dicke bat, wie die Epithellage, geht allmählich in eine Lage äber, welche nicht mehr den gleichmässigen Bau zeigt, sondern mebr 21 Gruppen angeordnet ist, welche getrennt sind durch helle Bezirke, in

Archiv f. pathol, Anat. Bd.129. Hft. 3. 
denen die Zahl der Kerne eine viel geningere, ihre Form länglich ist. Wavche von den gefässbaltigen Grupper zeigen nicht eine gleichmässige Vertheilung der Zellkerue, soudern es fallt auf, dass an manchen Stellen die Korne ganz dicht angehäuft sind. In diesen kernreichen Bezirlen finden sich nun die anfänge der Fettbildung.

Bei der Betrachtung mit stärkster Vergrösserung siebt man an den Stellen, wo sich die regelmässige Anordnung der Kerne findet, in ziemlicher Kntfernung von einander Kerne liegen, die meist eine ovale Gestalt haben, ganz fein granulirt sind, und Kernkörperchen nicht erkensen lassen. Nur bei einigen dieser Kerne lässt sich noch mit Sicherheit ein Zellleib nachweisen, die meisten Kerne liegen vollständig frei in der feinfasrigen, an manchen Stellen auch feinkörnigen Intercellularsubstanz. Die Färbung der Kerne ist durchweg eine sehwach rothe, nur wenige Kerne sind so schwach gefärbt, dass sie noch gerade als solche erkannt werden können, letztere haben meist eine mehr rundiche Form.

An den zellenreichen Stellen finden sich genau dieselben Zollkerne, nur sind sie hier dicht an einander gelagert, so dass nur eine geringe Menge derselben feinfasrigen bezw. feinkörnigen Intercellularsubstanz dazwischen zu liegen scheint. Bei genanerer Betrachtung erweist sich die Zwischensubstanz als der zu den Kernen gehörige protoplasmatische Zellleib; da aber die Kerme sehr dicht liegen, ist eine deutliche Trennung der einzelnen Zellen von einander unmöglich. Diese Zellen zeigen nun folgende Vorgänge. An manchen bemerkt man deutlich, wie sich unmittelbar an den schön roth getärbten, rundlichen Kern in den Zelleib ein kleiner Fettropfen einlagert, der manchmal nur erst so klein ist wie der Kern. Dieser Fettropfen ist in anderen Zellen grösser, drängt in der Zelle den Kern schliesslich ganz an die Zellenwand und macht aus einem ovalen einen mehr länglichen halbmondformigen. Zunächst ist noch zwisehen diesen so sich bildenden Fettzellen oine kernreiche, deutlich erkennbare Intercellularsubstanz vorhanden, allmäbHich wird diese undeutlich, man trifft dann in dem Gesichtsfeld nur Bezirke, wa eine Fettzelle neben der anderen liegt. Allmählich treten nun mehrere solche jugendlichen Fettzellen zusammen, confluiren und bilden so durch Confuenz einer grossen Anzahl solcher Zellen einen sogenannten Fettzellenverband. Fig. 5 zeigt uns solche Bilder, wo sich in einer Zelle mohrere Fettropfen befinden, die noch nicht confluilt sind, sondern von einer gemeinsamen Zellnembran umgeben sind. Daneben finden sich solche Entwickelungsstadien, wie sie H. Sehmidt in seiner Arbeit bei der Entwickelung des Fettgewebes beschrieben hat, wo unter allmäblichem Hinzutreten nener zelliger Elemente zu einer Fettzelle Fettzellenverbände entstehen, bis sie die Grösse der fertig entwickelten Form erlangt haben. Man trifft bei dieser Bildung alle Stufen der Entwickelung; lagern sich zwei Zellen an einander, so erscheinen schöne 8 förmige Figuren, an deren Polen sich die Kerne befinden; sind die Fetttropfen confluirt, so erhält man Figuren, welche einem Siegelring mit doppelten Steinen an entgegengesetzten Enden gleichen. Schliesslich finden sich Bezirke, namentlich in der Nähe von Gefässen, wo auch die zwischen 
den Fettzellen liegenden Kerne nicht in solcher Zahl mehr vorhanden sind, sondern das Fettgewebe schon einen mehr fertigen Eindruck macht.

Endlich finden sich längliche Faserzüge, deren Fasern zahlreiche längliche ovale Kerne enthalten; ob es sich hier um Bindegewebszellen, oder um Jugendzustände von Muskel oder Nerven handelt, lasse ich dahingestellt.

Epikrise: An dem Unterhautzellgewebe dieses 6 monatlichen Embryo lässt sich die Entwickelung des Fettgewebes aus dem Schleimgewebe Schritt für Schritt verfolgen. In dem Protocoll wurden zwei Bezirke unterschieden, einer, in dem die Zellkerne in gleichmässiger Weise durch die ganze Intercellularsubstanz vertheilt waren, und ein anderer, wo massenhafte Kerne erwacht sind. Die Bezirke von der ersten histologischen Struktur zeigen den ausgesprochenen histologischen Bau des Schleimgewebes; die zweite Gruppe zeigt die Umwandlung des Schleimgewebes in Fettgewebe. Zunächst erwachen zahlreiche Kerne in der Intercellularsubstanz, so dass fast ein Kern immer dicht neben dem anderen liegt; die Intercellularsubstanz ist kernhaitig geworden. Diese erwachten Kerne nehmen nun aus der Intercellularsubstanz Protoplasma auf, und bilden sich so zu fertigen Zellen um. Diese erwachten Schlummerzellen nehmen nun Fetttropfen auf und bilden sich so zu ächten Fettzellen um, dabei kann man alle Stufen der Entwickelung verfolgen, zuoächst sind die Fetttropfen noch klein, der Kern noch rundlich, und die jungen Fettzellen liegen in einigen Abständen von einander, und werden durch eine sehr kernreiche Intercellularsubstanz getrennt. Allmählich werden die Tropfen immer grösser, die Fettzellen wachsen und berühren sich schliesslich. Mehrere solche mit Fetttropfen angefüllten Zellen confluiren, und bilden sich zu den Zellen um, die man bis jetzt als ächte Fettzellen in der Histologie bezeichnet. Die Bildung geht aber auch so vor sich, dass sich an eine junge Fettzelle zunächst Zellen ohne Inhalt von Fettkörpern anlagern und erst, wenn sich eine gewisse Anzahl solcher Zellen angelagert hat, eine Aufnahme von Fetttropfen stattfindet. So zeigt sich denn, dass wie $H$. Schmidt auch in seiner Arbeit über Fettgewebe beschrieben hat, bei der Entwickelung des Fettgewebes, das, was bisher als Fettzelle wurde, nicht eine einzige Zelle ist, sondern einen sogenannten Fettzellenverband bildet.

Aus dem Schleimgewebe bildet sich so das Fettgewebe, $30^{*}$ 
dass zunächst Schlummerzellen auftauchen, wahrscheinlich sich durch Theilung vermehren, Fett aufnehmen und durch Anlagerung immer neuer Zellen, welche mit der Membran des Fetttropfens verschmelzen, Zellverbände mit grosser centraler Fettkagel bilden.

Das Schleimgewebe, wie es in den beiden letaten Fällen von dem subcutanen Unterhautgewebe der Embryonen beschrieben ist, unterscheidet sich also wesentlich von dem Schleimgewebe des Nabelstranges. Zunächst deutet die histologische Beschaffenheit darauf hin, dass wir es hier mit einem anderen Gewebe zu thun haben; einmal fehlen die grossen anastomosirenden Gewebszellen, die dem Nabelstrang sein charakteristisches Gepräge aufdrückten, die Zellen sind hier meist rund und entbehren jeden Ausläufers, andererseits hat die Grundsubstanz eine mehr gleichmässig homogene Struktur mit nur geringer Andeutung einer Faserung. Vor allen Dingen aber beweist hier die Entwiokelung von Fettgewebe aus den Zellen des Schleimgewebes, dass dieses Schleimgewebe als Aequivalent des Fettgewebes aufzufassen ist.

Wir haben somit bereits zwei verschiedene Arten von Schleimgewebe kennen gelernt, und dürfen also nicht sagen: Das Schleimgewebe ist sowohl Vorstufe des Bindegewebes als des Fettgewebes", sondern wir müssen sagen: Bei der Entwickelung des Bindegewebes beobachtet man eine diesem angehörende Modification ron mucinhaltigem Gallert- und Schleimgewebe, und bei der Entwickelung des Fettgewebes beobachtet man eine hiervon verschiedene Modification des Schleimgewebes, oder anders ausgedrückt: Bindegewebe und Fettgewebe besitzen je einen ihnen eigenartigen schleimigen Uebergangszustand während ihrer Sntwiokelung (Rollet), den Status mucosus des betreffenden Gewebes.

Fall 5. Senile (physiologische) Atrophie des subpericardialen Fettgewebes eines 67jährigen Mannes.

Es handelt sich um gallertiges Fettgewebe des Herzens eines an perfoiriem Magengeschwür auf der hiesigen medicinischen Klinik behandelten $67 j a ̈ h r i g e n$ Individuums.

Die mikroskopische Untersuchung des frischen Objectes giebt nach Fssigsünrezusatr eine deutliche Meinreaction: das Mucin ist in Form von feinsten 
Fäden, die in allen Ricbtungen das Gesichtsfeld durchziehen, geronnen, zwischen den Fäden liegen Zellen von Spindel- und seltener Sternform mit deutlich granulirten Kernen, an denen man noch als Ueberbleibsel der früheren Fettzellen kleinste gelbe Fetttropfen und Pigmentkörner liegen sieht. Hin und wieder finden sich Saftkanälchen und Capillaren mit deutlichen Kernen in den Wandungen.

Es werden zur mikroskopischen Untersuchung Stücke in Flemming'sehe Lösung gelegt, in Alkohol gebärtet; die Färbung geschieht mit AnilinwasserSaffranin.

Bei der Betrachtung mikroskopischer Schnitte mit schwacher Vergrösserung siebt man in einer homogenen Grundsubstanz, die schwach graurosa gefärbt ist, durch das ganze Präparat verstreut als feinste rothe Pünktchen Kerne liegen, die an manchen Bezirken durch sternförmige Ausläufer mit einander in Anastomose treten, so dass dadurch in diesen Bezirken die Grundsubstanz wie von einem Maschenwerk feinster Fäserchen durchsetzt erscheint. Daneben sieht man Blutgefässe theils quer, theils längs getroffen, an manchen Stellen intensiv schwarz gefärbte Pünktchen von wechselnder Grösse, namentlich ut die Kerne herum; es sind dies durch Einwirkung der Osmiumsäure schwarz gefärbte Fetttropfen.

Bei der Untersuchung mit stärkster Vergrösserung liegen in einer feinbörnigen, bei der Betrachtung ohne Blende homogenen, durchsichtigen, schwach rosà gefärbten Intercellularsubstanz in bedeutenden Abständen Zellen, die nur in ganz geringer Anzahl runde Gestalt baben, meist aber schöne Sternformen besitzen, dadurch dass diese Zellen mit granulirten, rundlichen Kernen, um welche herum meist kleinste Fetttröpfchen sich gelagert haben, nach verschiedenen Richtungen lange Fortsätze aussenden, die an vielen Stellen mit Ausläufern von benachbarten Zellen in Verbindung treten; dadurch entsteht ein Maschenwerk, wie es schon bei schwacher Vergrösserung sichtbar wird. An diesen Zellen lässt sich nun die Umwandlung derselben in Saftkanälchen verfolgen. Die Ausläufer sind nehmlich in der Nähe der Kerne doppelt contourirt, beide Contouren laufen später jedoch zusammen und endigen als feinste Fasern. Dort nun, wo die Ausläufer mit Ausläufern benachbarter Zellen anastomosiren, zeigt sich an manchen Stellen dasselbe Bild, d. h. in der Nähe des Kernes ist der Ausläufer doppelt contourirt, beide Contouren Jaufen dann zusammen und bilden ungefähr in der Mitte zwischen beiden Zellen einen soliden Strang, dann trennen sich die Contouren wieder, bis sie zum nächsten Zellkern gelangen ${ }^{I}$ ). Allmählich wird nun auch der mittelste Theil dieser verbindenden Faser hohl, und beide Zellkerne sind dann durch eine feine Röhre mit einander verbunden. So trifft man nun durch das ganze Präparat diese kleinsten Capillaren, an deren

1) Bekanntlich trifft man im Schwanz der Larven von Rana temporaria, sowie im Granulationsgewebe oder bei der Organisation von Thromben gleiche Bilder an, denen man erst später ansehen kann, ob die zarten Röhren dem Blut- oder Lymphgefässsystem angehören. 
Waadungen wan nach die Kerne der Gewebszeilen liegen sieht, bispeilen liegen anch die ganze Wand entlang nur feinste, intensiv schwarz gefarble Fettröpfchen. Manche Capillaren oder Saftkanäle zeigen in weiten Strecken geine Kerme mehr, nur zu Gruppen vereinigte Fettropfen deuten noch an, dass früher sich hier eine mit Fottröpfchen angefülte Zelle befunden hat.

Neben diesen Zellen nun, die durch lange Ausläufer in Verbindung steher, finden sich nun in der Intercellularsubstanz einmal vollständige Zellen, deren heller, durchscheinender, protoplasmatischer Leib sich sehr schön von der feinkörnigen, schwach rosa gefärbten Intercellularsubstanz abhobt - die Kerne haben denselben Charakter wie die Kerne der anastomosirenden Zellen - dann freie Kerne, vielfach noch von feinsten Fetttröpfchen umlagert, dann schwach rosa gerade noch als solche erkenbare Zellkerne, endlich nur Gruppen von feinsten Fettröpfehen von ganz verschiedener Grösse. Von vollständig entwickelten Eettzellen ist nichts mehr zu sehen.

Epikrise: Es handelt sich in dem vorliegenden Fall um oine Umwandlung des normalen subpericardialen Fettgewebes in gallertiges Gewebe; hervorgerufen ist diese Umwandlung durch aine allgemeine schlechte Ernährung: das Individuum, 67 Jahre alt, hatte schon seit langer Zeit an einem Ulcus rotundum ventriculi gelitten, aus dem jedenfalls zu wiederholten Malen Blutungen erfolgt waren, was die Anämie sämmtlicher Organe als sicher annehmen lässt; dazu kommt noch, dass auch durch die Vorgänge im Magen die Verdaung erheblich gelitten hat. Dass diese Ernährungsstörung schon längere Zeit bestandes hat, beweist der Umstand, dass auch die schleimige Substanz, die aus dem Fettgewebe hervorgegangen ist, schon älteren Datums ist: denn einmal finden sich in dem Präparat nirgends mehr vollständige Fettzellen, ferner ist nur noch an sehr wenigen Stellen ein directer Uebergang der Gewebszellen in die Intercellularsubstanz zu verfolgen; diese Prozesse haben sich längst abgespielt, die Gewebszellen sind in der Intercellularsubstanz in die Schlummerform übergegangen. In dem vorliegenden Falle finden sich nur noch die Uebergänge der Gewebszellen in Saftkanälchen. Man kann dabei alle Stufen der Entwickelung verfolgen: der Zelleib zieht sich zu langen Fasern aus, die mit den Fasern benachbarter Zellen anastomosiren, die anfangs soliden Faseru werden hohl und bilden so die Kanälchen, an deren Wandungen man dann noch die Kerne manchmal hohlpfannenmässig gehogen liegen sieht, allmählich gehen die Kerne in den Schlum- 
merzustand über, es bleiben dann nur vollständig kernlose $\mathrm{Ka}$ nälchen übrig, an deren Wandungen man vielleicht noch als Andeutung und Ueberbleibsel der früheren Zellen feinste intensiv schwarz gefärbte Fetttröpfchen liegen sieht. Im Innern der Röhrchen finden sich weder rothe noch farblose Blutzellen. Ein wesentlicher Unterschied dieses schleimigen Gewebes von den Schleimgeweben der vorigen Gruppe besteht in dem Vorhandensein des Pigmentes um die Kerne; dieses Pigment deutet stets darauf, dass es sich um Endstadien von pathologischen Vorgängen handelt, und beweist somit, dass dieses gallertige Fettgewebe wieder verschieden ist von den Geweben, die vordem beschrieben sind.

Fall 6. Pathologische Atrophie des Fettgewebes im Nierenhilus eines an Diabetes mellitus und Phthisis pulmonum gestorbenen 36 jäbrigen Mannes.

Die Untersuchung mit stärkster Vergrösserung an gefärbten Präparaten - denn die Untersuchung des frischen Objectes und des gefärbten mit schwacher Vergrösserung zeigt dasselbe Bild wie iw vorigen Fall - ergiebt zahlreiche Kerne an der Wand von Saftspalten, wenige in den Spalten; einige Saftspalten sind jedoch schon kernlos. In den übrigen Punkten gleicht das Bild vollständig dem des vorigen Präparates.

Epikrise: Auch hier handelt es sich um die Umwandlung des normalen Fettgewebes des Nierenhilus in eine schleimige gallertige Substanz; auch hier ist diese Umwandlung hervorgerufen durch eine allgemeine schlechte Ernährung. Das Individuum, ein 36jähriger Mann, hatte an Diabetes mellitus gelitten, dazu hatte sich eine tuberculöse Erkrankung der Lungen gesellt, die auch schon längere Zeit bestand, mit neuen Recidiven in der letzten Zeit. Gerade wie im vorigen Fall ist die Umwandlung des Fettgewebes eine ziemlich abgelaufene. Von Fettkörpern und Resten von Fettzellen ist nichts mehr zu sehen: dieselben haben sich in eine schleimige Substanz umgewandelt, dieser Prozess ist abgelaufen, nirgends kann man mehr deutlich den Uebergang der Zellen in Intercellularsubstanz verfolgen. Auch die Saftkanälchen sind in fast allen Theilen vollständig ausgebildet, sie erscheinen als lange, mit kernhaltigen Wandungen versehene Spalten, nur hier und da sind Spalten ohne Kerne. 
Ifall 7. Umbuldung ron Fetrgewebe in Sobleingewebe wh gleichzeitiger Wacherung des letzterea.

Myxom des Nierenbilus.

Es handelt sich um eine Geschwulst der linken Niere (Dissert., Hans Seblüter, Greifswald 1890), welche das ganze eigentliche Nierenparenchym fast vollständig verdrängt hat, so dass nur eine etwa $1 \frac{1}{2}$ mm dünne Schicht übrig geblieben ist, in der man Rinden- und Markscisicht nicht mehr erkennen kann. Von dieser sebmalen Zone quillt auf dem Durchschnitt ein Gebilde hervor, das augenscbeinlich als Tumor imponirt, es ist ein zähes, schleimiges Gewebe, von gelber, durchscheinender Farbe und in unregelmässiger Anordnung ron feinen, grauweissen, bindegewebigen Strängen durchzogen, das makroskopisch ganz den Eindruck eines Myxoms macht und auf Essigsäurezusatz die Mucinreaction giebt. Die Innenfäche der Calices und des Nierenbeckens ist nicht von normaler Schleimhaut überzogen, sondern ron einem bellrothen, sammtartigen, frischen Granulationsgewebe bekleidet, das ron einer dicken Wand ron grauweissem Bindegewebe umgeber ist.

Das Stroma des frischen raikroskopischen Bildes besteht in der Hauptsacbe aus derberen und feineren Bindegewebszügen, die hier und da Bindegewebskerne erkennen lassen, weiterhin aus Blutgefässen, stellenweise in grösserer, stellenweise in geringerer Menge, schliesslich aus einer homogenen Grundsubstanz, die aber auf Zusatz ron Essigsäure als ein feines Fasernetz hervortritt. In dem Stroma eingebettet liegen Zellen von verschiedener Form, Grösse und Anordnung. Zunächst rothe Blutkörperchen sowohl vereinzelt, als in grösseren und kleineren Haufen zusammen, erhalten und zerfallen. Dann eine Rundzellenform von wechselnder Grösse und $z$ war von der zweifachen bis in einzelnen Fällen zur zehnfachen Grösse eines rothen Blutkörperchens über das ganze Bild verstreut. Von diesen $Z$ ellen haben die kleineren in der Mehrzahl einen deutlichen centralen Kern und Protoplasmaleib, während die grösseren ein meist vollständig granulirtes Aussehen haben, selten einen Kern und dann meist mehrere von unregelmässiger Form excentrisch liegend. Weiterhin sieht man Zellen von mehr spindelformiger Gestalt an versehiedenen Stellen in grösserer Anzahl, an auderen vereinzelt. Diese senden feine Ausläufer ans, und verbinden sich dadurch zum Theil mit einander. Dann eine Rundzellenform meist in grösseren Haufen, beerdweise angeordnet und dann ohne erkennbare Grundsubstanz, aber auch vereinzelt über das ganze Bild zerstrent liegend. Diese sind etwas kleiner wie rothe Blutkörperchen und besitzen einen deutlichen Kern, der nur von einem dünnen Saur Protoplasma umgeben ist. Schliesslich vollständig fettig degenerirte Zellen, sowie auch Fettzellenverbände von verschiedener Grösse.

Der mikroskopische Befund an gehärteten und mit Anilinwasser-Saffranin gefärbten Schnitten ist folgender: In einem Stroma, das theils eine feinkörnige, theils eine feinfasrige Struktur hat, wobei die Fasern vielfach in einander verschlungen und verfilzt sind, liegt eine grosse Zahl Rundzellen 
von wechselnder Grösse; von diesen Rundzellen baben die kleinsten, die nur wenig grösser sind als rothe Blutkörperchen, einen deutlichen, centralen, granulirten Kern, der meist so intensiv roth gefärbt ist, dass Kernkörperchen zu erkennen unmöglich wird, und eine schmale ringformige Zone von Protoplasma, das meist ungefärbt geblieben ist; die grösseren Zellen haben ein stark granulirtes, intensiv roth gefärbtes Protoplasma, so dass der Kern undeutlich wird, meist gar nicht mehr erkannt wird. Daneben finden sich Zellen von mehr spindelformiger Gestalt mit Endothelkern, welche in weit geringerer Anzahl vorhanden sind als die kleinen Rundzellen, und einen deutlich granulirten, bedeutend schwächer gefärbten Kern wit einem oder mehreren intensiv roth gefärbten Kernkörperchen.

Die Mehrzahl der kleinen Rundzellen nun, die in bedeutender Ueberzahl das Gesichtsfeld beherrschen, lässt sowobl Kern wie Zellleib deutlich differenzirt erscheinen, die Färbung der Kerne ist eine gleichmässige; neben dieser Form finden sich nun von derselben Zellart nur freie Kerne, um die herum kein protoplasmatischer Zellleib mehr zu erkennen ist; allein, während die vollkommen intacten Zellen meist in einer feinfasrigen, deutlich verfilzt erscheinenden Intercellularsubstanz liegen, fällt an den freien Kernen auf, dass sie von einer feinkörnigen Intercellularsubstanz umgeben sind. Diese freien Kerne treten nun noch weiterbin in Beziehung zu der Intercellularsubstanz. Zunächst wird die Färbung der Kerne eine ungleiche: neben intensiv roth gefärbten Kernen findet sich ein Bezirk, wo die Kerne blasser werden, bis schliesslich nur noch die Kernkörperchen deutlich erkannt werden können. Allmählich verblassen auch diese, endlich deutet nur noch ein schwacher rosiger Schimmer die Lage der früheren Kerne an, so dass es den Eindruck macht, als ob der Kern ungenügend gefärbt wäre. Dieselben Kerne können nun noch auf anderem Wege in den Schlummerzustand übergehen, indem sie in verschiedenen Kerntheilen verschieden stark gefärbt werden, so dass sie dadurch ein granulirtes Aussehen bekommen und den Eindruck hervorrufen, als ob eine Körnung im Kern auftritt. Allmählich lösen sich diese Kerne auf, und man sieht dann Stellen, wo in der Intercellularsubstanz mebrere rothgefärbte Zellkernreste liegen.

Neben diesen Stellen, wo die Zellen eine gewisse Beziehung zur feinkörnigen Intercellularsubstanz zeigen, finden sich nun andere Stellen, wo dieselben Rundzellen (Zellen vom Typus c) in Beziehung treten zur feinfasrigen Intercellularsubstanz. Man sieht nebmlich in gewissen Bezirken, die gegen die Bezirke mit den oben geschilderten Vorgängen allerdings bedeutend in den Hintergrund treten, wie die kleinen Rundzellen nicht mehr eine kuglige Form haben, sondern mehr spindelförmig werden, die Kerne, welche dieselbe intensiv rothe Färbung zeigen wie die der Rundzellen, werden länglich gestreckt, und gewinnen dadurch eine Aehnlichkeit mit den oben beschriebenen Endothelkernen, sie unterscheiden sich jedoch wesentlich besonders durch ihre gesättigte Tinction von den Eudothelzellkernen. Diese langgestreckten spindelförmigen Zellen, die an manchen Stellen in grösserer Anbäufung, an mancben vereinzelt liegen, senden lange Ausläufer aus und 
treten dadurch mit einander in Verbindung, so dass man in Easerzingen von Zeit zu Zeit auf diese länglichen Kerne stösst.

Epikrise. In dem eben beschriebenen Gewebe bieten das Hauptinteresse die kleinen Rundzellen, die auch in ibrer Zabl bei weitem überwiegen vor den anderen Zellarten; als was sie genetisch aufufassen sind, lasse ich unentschieden, entweder kann es sich dabei um Leukocyten oder um Proliferationsvorgänge der Bindegewebszellen handeln, welche hervorgerufen sind durch langdauernde und immerwährende Reize oder die Rundzellen stellen Jugendformen der Endothelzellen vor. Der Rueiz hat nun auf das Gewebe so gewirkt, dass er zunächst in den Geweben oine grössere Saftströmung hervorgerufen hat, wodurch den Gewoben eine grössere Menge Ernährungsflüssigkeit zugeführt wurde. Dieser Ueberschuss an Ernährungsfïssigkeit wirkte anregend auf die schlummernden Gewebszellen, sie erhalten genügend Ernährungsmaterial and erwachen aus ihrem Schlummerzustand. Daher kommt es denn auch, dass das vorliegende Gewebe so viele Zellen enthält. Diese erwachten Zellen nun, seien es Bindegewebszellen oder Fettzellen, betheiligen sich an dem Aufbau des Myxomgewebes: ein Theil wird verwandt zur Bildung einer feinfasrigen Intercellularsubstanz, ein anderer zur Bildung einer feinkörnigen; beide Vorgänge sind oben beschrieben; haben sie diese Bildungsvorgänge durchgemacht, so sind sie zugleich in den Schlummerzustand übergegangen. Es zeigt sich also, dass die Intercellularsubstanz nicht von den Zellen abgeschieden wird, sondern selbst aus Zellen besteht; ob diese Zellen später wieder einmal erwachen können, bleibt späteren Forschungen vorbehalten, nach dem hier erörterten Befunde ist es zwar wahrscheinlich, aber nicht sicher zu entsoheiden.

Fall 8. Schleimige Umwandlung von Bindegewebe bei chroniseher Entzündung. Ulcus cruris.

Von einem Ulcus cruris werden an den Randbezirken Stücke excidirt, in Elemming'scher Lösung fixirt, in Alkohol gehärtet und mit Saffranin gefärbt.

Bei der Betrachtung mit schwacher Vergrösserung gewabrt man 4 Schichten. Am weitesten von der Oberfäche entfernt liegt eine schmale Zone von vollständig fertigem Fettgewebe, dessen Fettzellenverbände als kleinste helle kreisrunde durchsicbtige Figuren dicht an einander gelagert sind und zwischen sich noch hie und da Kerne erkennen lassen. Am Rande des Präparates erscheinen die Fettzellen durch Einwirkung der Osmiumsäure intensiv schwarz 
gefärbt. Auf diese Fettgewebslage folgt näher der Oberfläche eine Lage ganz straffen Bindegewebes, das eine deutliche fasrige Struktur zeigt und sebr zellenarm erscheint. Dieser Bindegewebsschicht schliesst sich eine mehr homogene, durchsichtige Lage an, in der man noch einzelne Fasern erkennen kann, und die dentlich zellenreicher wie die vorige Lage ist. Als vierte Lage folgt wieder eine Bindegewebslage, die keine deutliche Faserung erkennen lässt und ziemlich zellenreich erscheint.

Bei der Betrachtung mit stärkster Vergrösserung besteht das Fettgewebe, die unterste Lage, aus dicht an einander gelagerten fertigen Fettzellenverbänden, welche theils kernlos sind, theils nur an den Berührungspunkten unter einander Kerne enthalten, die meist langgestreckt oder oval, schwach rosa gefärbt sind und entweder ein oder mehrere Kernkörperchen erkennen lassen.

An diese Fettgewebslage schliesst sich die breite Lage des straffen Bindegewebes an. Diese Lage besteht aus breiten straffen Fasern, welche hellgelb gefärbt sind, und durch zahlreiche Saftspalten aus einander gedrängt erscheinen. Diese straffen Fasern verflechten sich vielfach in einander, so dass sie theils quer theils längs getroffen sind. Die mittlere Zone dieses Bindegewebes ist am kernärmsten; man triff hier nur wenige Kerne in den Fasern, eine grössere Zahl liegt an den Bündeln und giebt sich dadurch als zu den Saftspalten gebörig zu erkennen. Die Kerne sind langgestreckt, rosa gefärbt, mit deutlich differenzirter Kernmembran und Kernkörperchen. Je mebr nun sich diese Zone dem dritten Bezirke nähert, um so zellenreicher wird das Bindegewebe und namentlich treten bedeutend mehr Kerne in den Bindegewebsfasern auf. An der äussersten Grenze der Bindegewebsschicht findet man, dass die Fasern vielfach ron einander gedrängt sind, in den Lücken findet sich eine feinkörnige bei Betrachtung ohne Blende bomogen erscheinende Substanz, in welche Zellen eingelagert sind, von denen eine grosse Zahl von kleinsten intensiv schwarz gefärbten Fetttröpfchen umlagert ist. Diese Zellen sind theilweise vollständig fertig gebildet, d. h. sie haben eine entweder mehr längliche Form, feingranulirtes Protoplasma und einen Kern vom Typus der oben beschriebenen Bindegewebskerne, oder mebrere Kerne, so dass sie leukocytenähulich werden, theilweise ist aber der Zellleib nicht mehr erkennbar, sondern nur der freie Kern liegt in der hell durchscheinenden Grundsubstanz. Die leukoeytenähnlichen Zellen finden sich nun auch theils an, theils in den Bündeln des nächsten Bindegewebes. Genau dieselbe histologische Beschaffenheit wie die eben beschriebene zwischen den Bindegewebsfasern liegende Substanz zeigt die dritte Lage. Man bemerkt, wie Bindegewebszüge, die sehr zellenreich sind und sowohl die länglichen Zellen vom Endotheltypus wie die leukocytenähnlichen enthalten, in diese Substanz sich hineinziehen, sich allmählich auffasern und sich endlich in diese bomogene Substanz auflösen; am Ende solcher Fasern finden sich besonders zahlreich die beschriebenen Zellen. Die Grundsubstanz dieser dritten Lage besteht nun aus einem ganz feinen Filzwerk von Fasern, an deren Kreuzungspunkten man vielfach Zellen liegen sieht, theils im Charakter der ächten Bindegewebszellen, theils rom Typus der leukocytenähnlichen Zellen. An 
manchen Krewzungspunkten der Fasern foden sich aur frele Fetctöplchen. Jedoch nicht allein an den Kreuzungspunkten der Fasern, sondern auch frei in dev feinkörnigen Intercellularsubstanz fuden sich Zellen, die theils vollständig erbalten sind, theils ibren Zelleib vesloren haben, so dass nur der freie Kern übrig geblieben ist, man sieht aber noch, wie von diesen Kernen in sternförmigen Figuren feinste Fäserchen ausgeben, die wit den Fortsätzen anderer Zellen anastomosiren.

Nur ganz vereinzelt findet man Saftkanäle und zwar mit kernreichen Waadungen; die Kerne haben wieder den doppelten Typus der Gewebsellen.

Blutgefässe sieht man in dieser Zone nur sehr vereinzelt.

Was schliesslich die vierte Zone betrifit, so findet man hier lockeres Bindegewebe, welches in seinen Fasern zahlreiche Kerne enthält, welche ebenfalls wieder den doppelten Zellkerntypus haben. Von manchen Zellen kann man deutlich Bindegewebsfasern ausgehen sehen, welebe mit den fibrillären Leibern anderer Zellen zusammenhängen.

Epikrise: Was an diesem Ulcus cruris interessirt, ist die dritte Zone, bei der Bindegewebe eine schleimige Umwandlung erfahren hat. Schon in den dieser schleimigen Zone angrenzenden Theilen des Bindegewebes erwachen zahlreiche Bindegewebskerne, je näher man der schleimigen Zone kommt, am so zahlreicher werden sie. Man kann an der Grenze beider Bezirke deutlich die Umwandlung des Bindegewebes in Schleimgewebe verfolgen; die Bindegewebsfasern sind in Fibrillen zerspalten, der Leib der Bindegewebszellen bildet sich zu einer feinfasrigen vielfach sternförmig fasrigen Intercellularsubstanz um, schliessZich betheiligt sich auch der Kern mit Kernkörperohen an dieser Umbildung. Ein anderer Theil der Bindegewebszellen formt sich zu Saftspalten um, an deren Wandungen man dann noch die Kerne liegen sieht. Die Bildung der Zellen in Saftspalten ist eine sehr spärliche, was darauf hinweist, dass die schleimige Umwandlung noch nicht lange besteht, sondern ziemlich neu ist, da es vorläufig erst zur Bildung einer feinkörnigen, an manwhen Stellen feinfasrigen Intercellularsubstanz gekommen ist, und nur an einigen wenigen Stellen die schleimige Substanz schon älter ist, wo sich dann vereinzelt Saftspalten und Saftkanäle inden.

Da sich in dem straffen Bindegewebe sehr wenige Blutgefässe finden, so ist vielleicht diese Umwandlung des Bindegewebes in die schleimige Substanz so zu erklären, dass das mehr oberhalb liegende Bindegewebe unter einer zu schwachen Er- 
nährung steht, und deshalb genöthigt ist, sich in diese schleimige Substanz umzuwandeln, die optisch dem Schleimgewebe vollständig gleicht. Die zwei Arten von Zellen, welche bei dieser Umwandlung betheiligt sind, sind jedenfalls so aufzufassen, dass die eine Form vollständig entwickelte Bindegewebszellen sind, während die anderen, leukocytenähnlichen Gebilde, Abortivformen sind. Dass diese Zellen unzweifelhaft Bindegewebszellen sind, beweist schon allein ihre Lage sowohl in wie a n den Faserbündeln.

Während in den beiden Fällen von mucinöser Subcutis (3. 4) sich aus dem Schleimgewebe erst Fettgewebe entwickelte, dadurch, dass die Zellen des Schleimgewebes Fett aufnahmen, so ist hier in den folgenden 3 Fällen $(5-7)$ der Gang der Entwickelung der umgekehrte. Durch die Involution der Gewebe, wie sie sich im Alter physiologisch findet, und durch pathologische Umbildung ist das Fettgewebe wieder in einen Zustand übergegangen, auf dem es sich in jugendlicher Form schon einmal befunden hat (Virchow). Das Fett aus den Fettzellenverbänden-ist bis auf wenige kleinste Fetttröpfchen, die sich um die Kerne noch finden, von den in den Membranen erwachten Zellen verbraucht. Aus diesen Zellen ist durch Umwandlung wieder das ursprüngliche "adipöse" Schleimgewebe geworden. Der letzte Fall (8), bei dem es sich um fibröses Schleimgewebe handelt, giebt uns einen Uebergang zu den beiden nächsten Fällen.

Diese Zustände der Umbildung des Fettgewebes in Schleimgewebe finden sich nun ganz besonders an solchen pathologischen Vorgängen, wo durch Wucherungsprozesse Geschwülste entstehen, die so schnell wachsen, dass die Gefässneubildung mit dem Wachsthum der Geschwülste nicht gleichen Schritt halten kann, und sich dann das Fettgewebe in Schleimgewebe umwandelt, z. B. bei Myxomen, Fibromyxomen u. s. w.; von solchen Zuständen sollen später Beispiele angeführt werden, hier will ich nur 2 Fälle anschliessen, bei denen es sich um eine eigenthümliche Umwandlung in der Intima der Aorta und eine Neubildung beim Callus handelt.

\section{Fall 9. Aorta mit schleimiger Umwandlung der Intima.}

Es findet sicb auf der Innenfäche der Aorta oberhalb der Klappen eine eigentbümlich geléartige, von Blutfarbstoff rosa imbibirte Beschafienheit der Intima. 
Milroskopiseh zeigt sich bei der Untersuchung des frischen Objectes nach Wssigsäurezusatz das Bild der Wucinreaction mit theilweise zu Reilen angeordneten länglichen Kernen, die vielfach semmelartig gefornt sind und den Kindruck von amitotischen Theilungen machen.

Es werden Stäcke aus der Wand der Aorta excidirt, in Flemming'sche Lösung gelegt und in Alkohol gehürtet; die Färbung geschieht mit Saffranin.

Bei der Betrachtung mit schwacher Vergrösserung Iassen sich deutlich auf dem Längsschnitt der Aortenwand 4 Schichten unterscheiden: die Schicht der Adventitia kennzeichnet sich als die äusserste Lage durch den welligen Verlauf ihrer Bindegewebszüge, in denen man als kleinste rothe Pünktchen Kerme liegen sieht, die theils rundlich, theils mehr länglich erscheinen. Auf die Adventitia folgt als ungefuhr 12-15mal so dicke Schicht die Media: sie erscheint bomogen schwach rosa gefärbt, durchzogen in der Längsrichtung in regelmässigen Abständen von intensiv roth gefärbten feinsten Linien der elastischen Lagen der Media, die sich scharf von dem bomogenen Grunde abhoben; zwischen den elastischen Zügen liegen nun vielfach länglich gestreckte Kerne. Auf diese Media folgt eine graue, theils homogene, theils wellig erscheinende Schicht, in der vor Allem die in regelmässiger Anordnung sich findenden elastischen Züge fehlen; die meist rundlichen Keme sind gleichmässig durch die ganze Schicht zerstreut. Als vierte Lage folgt eine schmale, gleichmässig dunkelgraurothe Zone, dio fast vollständig jeden Kern entbehrt, in den innersten Lagen der Intima finden sich theilweise Anbäufungen von meist rundlichen Kernen.

Bei der Betrachtung mit stärkster Vergrösserung lässt die Grundsubstanz der dritten schleimähnlichen Lage zwei histologisch verschiedene Bezirke erkennen. Einnal ist die Grundsubstanz in gewissen der Media angrenzenden Bezirken im Grossen und Ganzen bindegewebig; in dentlich wellig verlaufenden Faserzügen liegen theilweise Kerne, die ganz schmal und langgestreckt sind und eine grosse Aehnlichkeit erbalten mit den Kernen der glatien Muskelfasern. Diese Kerne iu den Fasern sind schwach rosa geZärbt, haben eine etwas dunkler gefärbte Kernmembran, Kernkörperchen und Cbromatingerüst, und zeigen vielfach Einschnürungen, so dass dadurch gewisse semmelartige Figuren entstehen, wie sie sich bei amitotischen Theilungsvorgängen finden. Je mehr sich dieser bindegewobige Bezirk nun dem zweiten Bezirk nähert, um so mohr werden die Zellkerne rundlich, behalten aber vielfach ibre semmelförmigen Zusammenschnürungen, die Intercellularsubstanz verltert ihre fasrige Struktur und wird theils mehr feinkörnig, theils mehr feinfasrig. Die Intercellularsubstanz ist hier in zablreichen Richtungen und Ebenen von feinsten Saftkanälchen durchzogen, an deren Wandungen vielfach noch Zellen von dem Typus der Gewebszellen, manchmal nur noch schwach gefärbt, liegen. An wanchen Stellen trifft man auch innerbalb der Kapälchen Zellen liegen, die einen rundlichen Korn und nur einen schwachen Protoplasmasaum baben. Neben diesem Saftkanalsystem finden sich in der Intercellularsubstanz noch freie, meist rundliche Kerne; sie finden sich aber 
nur in sehr geringer Anzahl, es überwiegen entschieden die Zellkerne, welche an den Wandungen der Saftkanälchen und Saftlücken liegen.

Die vierte, am meisten dem Lumen der Aorta zugekehrte Lage erscheint homogen und so gleichmässig intensiv gefärbt, wie sich sonst schleimige weiche Substanzen färben. Sie ist fast vollständig kernlos, nur an einigen wenigen Stellen befinden sich sowohl längliche wie rundliche Kerne.

In der Media beben sich deutlich als scharfe, doppelt contourirte Linien die in Zügen verlaufenden elastischen Fasern hervor, an denen man hier und da meist bestimmten Bezirken angehörig in den Fasern Kerne von spindeliger Gestalt antrifft.

Auch in der Adventitia finden sich solche Bezirke, wo theils an, theils in den Fasern zahlreiche Zellkerne ohne Zellenleib liegen.

Epikrise: Es handelt sich um eine eigenthümliche Umwandlung der Intima der Aorta in eine dem Schleimgewebe sehr nahe stehende Substanz. Man kann in der Intima zwei Lagen unterscheiden, eine oberflächliche und eine tiefe. In der tiefen Lage, besonders in den obersten Theilen derselben hat sich das lose Bindegewebe zum grössten Theil in eine Substanz umgewandelt, die, wenn auch nicht dem Schleimgewebe gleichartig ist, doch sehr nahe steht. In den meisten Bindegewebsfasern sind die Kerne erwacht, die Fibrillen haben sich in eine schleimige Substanz umgowandelt, nur wenige Fasern haben sich erhalten. Diese Umwandlung der erwachten Schlummerzellen in diese feinkörnige Intercellularsubstanz ist ein abgelaufener Prozess, nur hier und da sieht man ganz vereinzelt, wie einige Zellen als Nachzügler sich direct in Intercellularsubstanz umformen. An dem vorliegenden Präparat spielen sich meist die späteren Prozesse, nehmlich die Umwandlung der erwachten Zellen in Saftkanälchen ab. Die ganze Intercellularsubstanz ist nehmlich durchsetzt von zahlreichen Saftspalten und Saftkanälchen, an deren Wandungen man noch vielfach Kerne liegen sieht; an den Stellen, wo die Saftspalten kernlos sind, sind nach Bildung der Saftspalten die Kerne schon wieder in den Schlummerzustand übergegangen. Optisch ruft diese oben als dritte Lage bezeichnete Schicht denselben Eindruck hervor, wie Schleimgewebe, nur die hier und da die Intercellularsubstanz durchziehenden Züge von Bindegewebe zeigen an, dass diese Substanz dem Schleimgewebe nur als verwandt aufzufassen ist. Was nun die äusserste, dem Lumen der Aorta zugekehrte, Lage der Intima betrifft, so 
zeigt sich schon an der gleichmässigen saftigea Fürbung, dass man es mit einem weichen schleimähnlichen Gewebe zu thun hat, dio vollständige Zellarmuth deutet darauf hin, dass hier der Prozess ein abgelaufener ist, die an oinzelnen Stellen sich zeigenden Zellkeme sind Nachzügler dieses Prozesses.

Was nun die Deutung dieser Prozesse in der Intima betrifft, so glaube ich, giebt dieser Prozess, der sich nicht nur in uer Aorta, sondern auch an den Semilunarklappen der Aorta findet, einen Ausblick für die Entstehung einer Endocarditis und Endoaortitis. In der Intima der Aorta findet sich nirgends an diesen pathologischen Stellen auch nur die gringste Andeutung eines Endothels; dass jede ihres Endothels beraubte Gefässintima dem vorbeiströmenden Blut Gelegenheit giebt Fibrin abzusetzen, ist bekannt. Es wäre also vielleicht auf diese Weise möglich, dass sich eine Endocarditis bildet, ohne dass gerade Bakterien mit bei der Entstehung der Endoc, betheiligt wären. Für die Aetiologie von Endocarditisfällen, wie sie sich manchmal nach chronischen Krankheiten entwickeln, würde dieses von grosser Bedeutung sein. Ich unterlasse es, hier näher auf den Punkt einzugehen, da schon von anderer Seite dieser Punkt zum Gegenstand einer Untersuchung gemacht ist; ich will ihn hier nur angedeutet haben.

Noch ein anderer Vorgang verdient genauere Betrachtung; er betrifft die Media. Die in den elastischen Zügen der Media erwachten Zellen, wie sie oben beschrieben sind, sind nun vielleicht im Stande, denselben Entwickelungsgang durchzumachen wie die erwachten Zellen der Intima, auch sie können sich in eine schleimige weiche Substanz umwandeln. Hat nun diese Umwandlung erst eine gewisse Dimension angenommen, resultirt nothwendiger Weise daraus, dass die Haltbarkeit der Gefässwand, die hauptsächlich zu Stande kommt durch die elastischen Lagen der Media, dem Blutdruck gegenüber leidet. Die weiche Substanz, die an Stelle der elastischen Elemente der Media getreten ist, giebt dem Blutdruck nach, die Gefässwand buchtet sich an dieser Stelle vor, es entsteht ein Aneurysma.

Diese Betrachtung kann vielleicht im Stande sein, die Lehre von der Entstehung der Aneurysmen, namentlich die Auffassung Thoma's, nach welcher die Aneurysmen hauptsächlich zu Stande 
kommen durch Ruptur der Media, wo sich das Blat dann in die Maschen der Adventitia hinein ergiesst, eine Umänderung erfahren zu lassen, auf die ich hier nur kurz hingewiesen haben will. Auch diese Frage ist zum Gegenstand einer genaueren Untersuchung gemacht worden (vgl. die Dissert. Straube: über Arteriitis deformans und Cronheim: Beitrag zur Histologie und Entstehung der spontanen Aneurysmen, Greifswald 1892).

\section{Fall 10. Callusbildung bei einer Fractura femoris eines an Larynxdiphtherie gestorbenen Kindes.}

Das vorliegende Präparat stammt von einem Kinde mit Fractura femoris, das an einer Larynxdiphtherie zu Grunde ging. Das linke Bein liegt stark auswärts rotirt und abducirt, der Oberschenkel ist verkürzt und verdickt. Bei Herausnabme des linken Femur ergiebt sich, dass die Musculatur fast in der ganzen Länge des Oberschenkels von Bämorrbagien durchsetzt ist, das Blut zieht sich in dunkelrothen Streifen zwischen den einzelnen Muskelbündeln hin. Das Femur zeigt eine ungefähr in der Frontalebene verlaufende Schrägfractur in der Mitte, die Bruchfläche ist $6 \frac{1}{2} \mathrm{~cm}$ lang. Nach Durchschneidung der Musculatur bängen die Knochen nicht mehr zusammen und lassen sich leicht an einander bewegen; das Periost ist in der Umgebung der Fracturstelle stark verdickt, die Knochenränder sind ganz scharf, die Bruchflächen sind durchzogen von elastischen, weichen, grauröthlichen bis grauweissen Massen. Von diesen weichen Massen werden Stücke in Alkobol gelegt und mit Saffranin gefärbt.

Bei der Untersuchung mit schwacher Vergrösserung sieht man in einer homogen gelblich erscheinenden Intercellularsubstanz zahlreiche Kerne als kleinste rothe Pünktchen, die sich ganz besonders in der Nähe von Gefässdurchschnitten angesammelt baben. Neben diesen kleinen Kernen finden sich noch in der Intercellularsubstanz gewisse Bezirke, wo sich vollständig erhaltene Fettzellenverbände za Gruppen angeordnet vorfinden und entweder als durch die Einwirkung der Osmiumsäure intensiv schwarz gefärbte Kügelchen oder als vollkommen durchsichtige helle Kreise erscheinen.

Bei der Betrachtung mit stärkster Vergrösserung löst sich das Bild in folgende Einzelheiten auf. An den Stellen, wo sich die Fettzellenverbände vollständig erhalten haben, erkennt man besonders an den Berührungsstellen schöne granulirte, roth gefärbte, wit Kernkörperchen versehene Kerne, die theils oval sind, theils eine mebr längliche, balbmondförmige Gestalt annehmen, sich aber immer wandständig in der Membran finden. Diese Fettzellenverbände haben nun in demselben Bezirk nicht dieselbe Grösse, sondern man sieht, dass die Zellen allmählich kleiner worden, ibr Fett abgeben, bis man endlich zwischen noch vollständigen Fettzellenverbänden Bezirke erhält, wo entweder nur noch Kerne liegen, deren Abstammung aus Fettzellen kleinste, sich um den Kern gruppirende Fetttröpfehen anzeigen, oder man Archiv f, pathol. Anat. Bd. 129. Hft. 8. 
vollständig intacte Gewebszellon mit schönem, meist ovalen, granulirten Kernen mit Kernkörperchen und meist etwas grauröthlichem Protoplazmaleib trifft. Von einigen dieser Gewebszallen, die meist in einer dem Schleimgewebe optisch gleichenden feinfasrigen Intercellularsubstanz liegen, nimmt der Protoplasmaleib sowobl eine mehr unregelmässige Form als auch mear homogene und dem Schleimgewebe ähnliche Färbung an, bis el von der Iatercellularsubstanz endich nicht mehr zu trennen ist; in dieser mebr bomogenen Intercellularsubstanz liegen dann nur freie ovale Kerne rom Typus der Endothelkerne. Auch diese Kerne betheiligen sich dann weiter an der Bildung der Intercellularsubstanz, sie färben sich zunächst intensiver, so dass eine Erkennung des Kernkörperchens unmöglich wird, lösen sich dann in verschiedene Theile auf, bis auch diese letaten Kernspuren endlich verschwinden.

Ein Uebergang der Zellen in Saftspalten und Saftucken ist nirgends zu beobachten.

An einzelnen Stellen finden sich noch heerdweise Anhäufungen von rothen Blutkörperchen, herrührend von durch die Fractur hervorgerufenen. Hämorrbagien in das Gewebe hinein.

Epikrise: Es handelt sich um eine Umwandlung von Bindegewebszellen und ganz besonders Fettzellen des Periosts in eine Substanz, die optisch dieselbe Beschaffenheit zeigt, wie das Schleimgewebe. Man kann zunächst den Uebergang der Fettzellenverbände in einfache Gewebszellen verfolgen, der grösste Theil der so entstandenen Gewebszellen formt sich auf dem oben beschriebenen Wege zu Intercellularsubstanz um; zu einer weiteren Entwickelung des Gewebes kommt es nicht, weder bilden sich Saftkanäle noch elastische Fasern aus den Zellen. Man kann also das vorliegende Gewebe als eine unentwickelte Form des Schleimgewebes auffassen, wo die Zellen sich nur erst zu Intercellalarsubstanz umgeformt haben, es zur Bildung von Saftspalten aber noch nicht gekommen ist.

Wir haben also bis jetzt zwei verschiedene Zustände des Schleimgewebes kennen gelernt, den fibrösen aufsteigend in Fall 1 und 2, absteigend in Fall 8, 9 und 10, und den adipösen $\mathrm{Zu}$ stand, aufsteigend in Fall 3 und 4, absteigend in Fall 5-7.

Das Bindegewebe des Callus des letzten Falles hat also bicht seinen normalen Entwickelungsgang durchgemacht, und sich zu Knorpel-bezw. Knochengewebe umgewandelt, wie es bei jedem normal sich entwickelnden Callus der Fall sein soll, sondern hat eine schleimige Umbildung erfahren, wie sie bei 
atrophischen Zuständen physiologisch am Knorpel vorkommt. Die Bezeichnung der schleimigen Erweichung wird vehmlich häufig gebraucht für Degenerationsvorgänge im Knorpelgewebe, z. B. in den Rippenknorpeln. Dass es sich dabei um etwas dem Schleimgewebe Vergleichbares handelt, nehmlich Erwachen von Zellen in der Grundsubstanz, Bildung von Saftkanälchen, Uebergang von Zellen in flüssige Substanzen, das hat Tenderich (Diss. Greifswald 1892) am Knorpel beschrieben. Es zeigt sich aber, dass dieser "Status mucosus" der Knorpel wiederum eine besondere Modification ist, welche erheblich von dem Status mucosus des Bindegewebes und Fettgewebes abweicht.

Dagegen gilt nach Virchow das gallertige die langen Röhrenknochen ausfüllende Knochenmark als ein Typus des Schleimgewebes, so dass ich auf dieses hier näher eingehen muss, um so mehr, als in den Präparaten Bilder vorgekommen sind, welche auch an den Knochenbälkchen die directe Umbildung der frei gewordenen Zellen zu Fettgewebe erkennen lassen.

\section{Fall 11. Atrophisches Knochenmark eines 89 jährigen Mannes (Fig. 2).}

Es handelt sich um das Knochenmark eines Femur von einem an Bronchopneumonie und Marasmus senilis zu Grunde gegangenen 89jährigen Individuum. Zur genauen mikroskopischen Untersuchung merden Stäcke in Flemming'scher Lösung und Alkohol gehärtet, und wit Anilinwasser-Saffranin gefärbt.

Bei schwacher Vergrösserung siebt man in der Hauptsache Fettgewebe, d. h. Fettzellenverbände, wie sie H. Schmidt bezeichnet hat, neben einander liegen, an deren Berührungspunkten Kerne als rothe Pünktchen hervortreten. Diese Kierne finden sich nur in der Peripherie, d. h. also anf der Grenze der Zellverbände, welche als runde helle durchscheinende Kreise erscheinen. An einigen Stellen nun sind die Kerne in so dichter Anordnung vorhanden, dass das Fettgewebe vollständig in den Hintergrund tritt, und hier nur Zelle an Zelle (bezw. Kern an Kern) liegt. An anderen Stellen wieder sieht man, wie $z$ wischen den Fettzellverbänden sich ein Gewebe befindet, welches leicht bläulichrosa gefärbt ist und Kerne erkennen lässt, deren Zahl jedoch bedeutend zurücktritt gegenüber den dichten eben beschriebenen Zellanhäufungen. Diese Zellanhäufungen stehen in gar keinem Verbältniss $z u$ den Gefässen, denn hier und da siebt man zwischen den Fettzellverbänden Gefässe lieğen, meist längs getroffene, ohne dass sich hier Zellanbäufungen finden, während die zellreichen Bezirke meist gefässarm sind.

Bei der Untersuchung mit stärkster Vergrösserung findet bei dem annäbernd normalen Fettmark Bestätigung, was H. Sehmidt in seiner Arbeit 
äber Wettgewebe beschrieben hat, dass nehwlich das, was man fruther allgemein als Fettrellen bezeichnet hat, nicht eine einzige Zelle ist, sondern einen sogenannten Zellenverband darstellt. Man findet nohmlich sowohl dort, wo mehrere als 2 Fettallen (nach der alten Auffassung) sich berühren, Kerne legen, welche eine mehr ovale Gestalt haben, deutliche Membran und Kernkörperchen erkennen lassen und manchmal Pigment um sich liegen haben, als auch an den tangentialen Berührungspunkten der Zellen Kerne von wehr länglicher Gestalt, so dass schliesslich sich Stellen finden, wo eine Fettzelle von einem Kranz ron Kernen umgeben ist, die in der Membran der Fottzelle liegen. Diese letzteren Stellen nähern sich schon den Stellen, wo sich die dichte Anbäufung der Zellen findet. Hier finden sich nicht mehr freie Kerne, wie es grősstentheils an den eben geschilderten Partien des Präparates, sondern meist vollständig ausgebildete Zellen, die meist dem Rundzellentypus angebören. Die Kerne der Zellen und mit ihnen die vollständigen Zellen zeigen einen wesentlichen Unterschied von den Zellen, wie man sie sonst im Bindegewebe antrifft, vor allen Dingen ist das Protoplasma mehr dunkel gefärbt, leicht körnig, der Kern, abgeseben von seinem grösseren Urafang, vollsaftiger und stärker granulirt. Der Zellleib ist ferner leicht rosa gefärbt und enthält an manchen Stellen Pigment in Gestalt von kleinen, stark lichtbrechenden, gelblichen Körnchen, die Kerne sind theils rund, theils mebr länglich gestreckt, verbalten sich jedoch in Bezug auf ihre Chromatinsubstanz ebenso wie die schon oben beschriebenen freien Kerne der Fetizellenverbände. Was die Grösse der Zellen anbelangt, so haben sie fast durchweg die Grösse von vergrösserten Bindegewebszellen. Einige Zellen treten jedoch aus diesem Rabmen heraus, sind mebrkernig und entsprecben Riesenzellen, wie man sie normaler Weise im Knochenmark antrifft.

Geht man nun noch einen Schritt weiter, so fudet man Stellen, wo die Anhäufung der Zellen nicht mehr eine so ganz dichte ist, sondern dazwischen eine Intercellularsubstanz auftritt, die eine dentliche Faserung zeigt, von der man nachweisen kann, dass sie direct aus den besctriebenen Zellen bervorgegangen ist. Es finden sich nehmlich Zellen, welche ihre runde Gestalt eingebüsst haben und melr sternförmige Figuren bilden (Fig. 2 StZ), indem sich direct aus dem Protoplasmaleib der Zelle Iange Ausläufer fortsetzen, sind die Kerne länglich gestreckt und gehören sie mehr spindeligen Zellen an, so haben die Zellen meist nur zwei Fortsätze, welche sich jedoch wiederum vielfach spalten und verästeln können (Fig. $2 \mathrm{SpZ}$ ). Die Umwandlung des Zellleibes zu Fasern schreitet immer weiter vor, man trifft dann Zellen, deren Protoplasmaleib sich auf der einen Seite schon vollständig zu Fibrillen umgewandelt hat, auf der anderen Seite aber noch vollständig erhalten ist. Schliesslich findet man freie Kerve in Fibrillengruppen liegen, Zellleib ist nicht mehr vorbanden, statt dessen aber ein Fasergerüst von feinsten Fasern (Fig. $2 \mathrm{Fk}$ ). Um manchen der freien Kerne finden sich noch kleine gelbe Pigmentkörnchen (Fig. 2 P). Schliesslich trifft man zwischen gewissen Fettzellenverbänden Stellen, wo gar keine Zellen mebr liegen, sondern nur ein Maschenwerk von feinsten Fasern sich vorfindet (Fig. 2 F). 
Wieder an anderen Stellen findet man grosse Riesenzellen, deren Protoplasma nicht gekörnt und schwach rosa gefärbt ist, und in seiner Struktur dem Schleimgewebe nahe kommt, deren Kerne meist ovale Gestalt haben, deutlich granulirt sind, und Kernmembran und Kernkörperchen hervortreten lassen. Bei diesen Riesenzellen kann man ihre Entstehung aus den Fettzellenverbänden verfolgen. Man siebt nehmlich Stellen, wo sich zwei oder mehrere Zellen, wie sie oben beschrieben sind, d. h. Rundzellen mit schwach rosa gefärbtem Zellleib und schönen runden bläschenförmigen Kernen, an eínander lagern, mit einander verschmelzen, und so durch einfache Confluenz grosse Riesenzellen bilden, von denen einzelne 6 oder mebrere Kerne erkennen lassen. Diese Riesenzellen bleiben nur theilweise auf dieser Stufe der Entwickelung stehen, andere wandeln sich wiederum ebenso wie es schon oben von den einfachen Zellen beschrieben ist, in ein feinfasriges Maschenwerk von (elastischen?) Fasern um. Die Umwandlung geschiebt ebenso wie bei den oben beschriebenen Zellen.

An einigen wenigen Stellen finden sich nun zwischen den Zellen des Fettmarkes kleine Knochenbälkchen mit Knochenkörperchen in den Knocbenhöhlen (Fig. $2 \mathrm{~KB}$ ). Der Rand dieser Knochenbälkchen besteht theilweise aus länglichen intensiv roth gefärbten erwachenden Kernen (Fig. 2 E, Z), wie man sie auch bei Erwachungszuständen im Bindegewebe antrifft, daneben finden sich Kerne, welche schon ein deutliches Chromatingerüst erkennen lassen und sich schon den Endothelkernen nähern. Diese Kerne liegen theils frei in den Membranen der angrenzenden Fettzellenverbände, theils haben sie einen protoplasmatischen Leib von Spindelform; letzterer anastomosirt mit Membranen benachbarter Fettzellenverbände, wie in Fig. 2 die Spindelzelle S.

Epikrise: Das vorliegende Präparat, Knochenmark von einem 89 jährigen Mann, ist deshalb lehrreich, weil man alle Vorgänge an demselben verfolgen kann bis zur Bildung einer Substanz, die man bisher als gallertiges Knochenmark bezeichnete. Das Knochenmark eines erwachsenen Individuums besteht in seinem grössten Theil aus ächtem Fettgewebe; auch hier findet man in der Hauptsache noch Fettgewebe, d. h. es liegen Fettzellenverbände neben einander, an den Berührungs- und Kreuzungspunkten finden sich einige Kerne. Beginnt nun in diesem Gewebe der Prozess der Atrophie, so erwachen die schlummernden Zellen der Verbände, die runden Fetttropfen werden rings umgeben von vielen Zellkernen, welche die Fetttropfen auseinanderdrängen; man trifft dann Stellen, wo zwischen den noch deutlich erkennbaren Fettropfen zahlreiche Kerne ohne Leib sich in den Membranen finden. Schreitet nun der Prozess weiter fort, so trifft man neben frei in den Membranen liegenden Kernen mehr und 
wehr ausgebildete Zellen, de liettroplen werken aufgebrauch, schliesslich finden sich Conplexe von zahlreichen vollständig entwickelten Zellen, von denen einige vielleicht noch keinste Fettröpfchen in ihrem Protoplasma beherbergea. Diese so aus dem Fettgewebe hervorgegangenen Rundzellen machen nur nach zwei Richtungen hin verschiedene Prozesse durch; der eine Theil wandelt sich in ein feines Maschenwerk von feinsten (elastischen?) Fasern um, zwischen denen jedenfalls eine Hüssigkeit oder: weiche Masse sich befindet, welche dem atrophischen Knochenmark die eigenthümlich weiche Beschaffenheit verleiht. An den gefärbten Präparaten ist nichts davon mehr nachzuweisen, weil diese weiche oder flüssige Masse heranggeflossen ist. Ein anderer Theil dieser Rundzellen braucht, um sich in dieses feine Faserwerk zu verwandeln, erst ein Mittelglied. Es lagern sich nehmlich mehrere Zellen an einander, confluiren und bilden schöne Riesenzellen, welche sich erst wieder in das feine Fasermark umwandeln. Alle Phasen dieser Entwickelung sind an dem vorliegenden Präparate zu verfolgen.

Die Vorgänge, welche sich an dem vorliegenden Object abspielen, lassen die Vermuthung auftauchen, dass das Fettgewebe, wenn es auch mikroskopisch überall dieselbe Struktur zeigt, doch an verschiedenen Stellen des menschlichen Organismus versohiedene Beschaffenheit hat, die besonders dann hervortritt, wenn das Fettgewebe gewisse pathologische Prozesse, besonders regressiver Art, durchzumachen hat. Während nehmlich das Fettgewebe des subcutanen Gewebes, wenn es unter schlechten Lrnährungsverhältnissen steht und atrophirte, sich umwandelt direct in ein Schleingewebe, welches die schon von Virchow als charakteristisch für das Schleimgewebe aufgestellte Struktur hat, so zeigt dieses vorliegende Präparat, dass das Fettgewebe des Knochenmarkes sich nicht in eine homogene schleimige Substanz umwandelt, sondern in feinste Fasern sich umbildet, zwischen denen jedenfalls eine Substanz suspendirt ist, die wahrscheinlich rein flüssig ist. Dass es kein Mucin ist, zeigt schon der Umstand, dass os mikroskopisch gar nicht zu erkennen ist, sondern gleich bei der Excision ausgeflossen ist. Es wïrde vielleicht ganz zweckmässig sein, eine Trennung zu machen zwischen der Tela mucosa, welche Vorstufe des normalen Fett- 
gewebes ist und später dessen atrophisches Endstadium wird, und der Tela mucosa oder dem Status mucosus des Knochenmarkes, welches als myelogenes Schleimgewebe zu bezeichnen ist. Mit andern Worten kann man sagen, dass das Schleimgewebe ein Zustand ist, in welchem Bindegewebe, subcutanes, pericardiales und Nierenfettgewebe, sowie das Gewebe der Knochen zur Erscheinung kommen können, ohne dass man den Status mucosus dieser Gewebe identificiren darf, denn jede Art des Schleimgewebes hat wieder ihre Besonderheiten.

Von Bedeutung sind auch die Vorgänge, die uns die sich im Knochenmark befindenden abgesprengten Knochenbälkchen zeigen. In den mittleren Theilen der Knochenbälkchen findet sich normale Tela ossea, d. h. in einer homogenen Grundsubstanz finden sich in Knochenlücken Knochenkörperchen, am Rande des Knochenbälkchens dagegen tauchen Schlummerzellen auf zunächst in Form von länglichen Kernen obne erkennbaren Chromatingehalt, dann werden die Kerne grösser, bekommen ein feines Chromatingerüst und Kernkörperchen, diese Kerne liegen nun schon vielfach in den Membranen der Fettzellenverbände, die unmittelbar an das Knochenbälkchen herangrenzen; manche Kerne ziehen jedoch auch Protoplasma an sich und werden zu grossen Spindelzellen.

Die sich findenden Knochenstückchen werden also abgeschmolzen dadurch, dass die Kalksalze aufgelöst werden, dass in den Randbezirken Kerne erwachen, diese späterhin sich zu fertigen meist spindeligen Zellen umformen, und diese so entstandenen fertigen Zellen dann durch Fettaufnahme zu den Zellen des Fettmarkes werden. Es lehrt dieser Vorgang, dass die Bildung des Knochenmarkes nicht nur durch Vermehrung und Wachsthum der Zellen im Knochenmark selbst vor sich geht, sondern dass zum Aufbau des Markes auch Knochenbälkchen verwandt werden, die durch Metaplasie direct Fettmark liefern. Die überaus reichhaltige Literatur siehe in den Lehrbüchern.

Dieselben Präparate, welche ein Zusammentreten der Knochenmarkszellen zu fetthaltigen Verbänden zeigen, enthalten auch Riesenzellen, welche nach unserer Auffassung ebenso gedeutet werden müssen.

Ueber die Bildung der Riesenzellen ist eine so ungeheure 
Titeratur vorhanden, dass ich hier nur ganz kura antühren möchte, dass sowohl im Knochenmark als auch in Sarcomen das Zusammenfliessen vieler Zellen zu einem grossen Verband ungleich häufiger vorkommt, als bisher angenommen wird. Eine der häufigsten Formen in welchen man diese Verbände antrifft, ist bekanntlich diejenige, dass ein grosses körniges Gebilde oft mit stachligen und nach verschiedenen Ebenen ausstrahlenden Fortsätzen eine grosse Menge von Kernen vorwiegend an dem Rande enthält, während die Mitte davon frei ist. Es handelt sich hier. bei nach unseren Beobachtungen um ein allmähliches Verschwinden und einen Uebergang der Kerne in die sogenannte Schlummerform, während nicht ausgeschlossen ist, dass gleichzeitig andere Kerne in demselben Verbande Theilungsfiguren zeigen. Einen Fall, bei welchem diese Entstehung der Riesenzellen durch regelmässige Aneinanderlagerung und Verschmelzang kleinerer Zellen besonders deutlich zu verfolgen ist, lasse ich in nächster Beschreibung folgen.

\section{Uebergang von Zellen in die körnige Grundsubstanz von Riesenzellen.}

Bei der Untersuchung eines frisch eingelegten und gehärteten Riesenzellersarcons fiel auf, dass die Grundsubstanz der Riesenzellen optisch voll ständig dieselbe Beschafienheit hatte wie das Schleimgewebe. Es wurden nun die Riesenzellen einer genaueren Untersuchung unterworfen, und es fand sich, dass die Grundsubstanz, die feinkörnig war, durch Unwandlung von Sarcomzellen entstanden war. Der Anfang dieser Umwandlung bildete eine siärkere Körnung und stärkere Färbung einer Sarcomzelle. Gegenüber dieser stärkeren Körnung des Protoplasma trat allmählich der Kern immer mehr zurück, blasste $a b$ und verschwand schliesslich ganz; es blieb mikroskopisch ein feinkörniger Klumpen von der Gestalt der früheren Zelle zurück. Von der Peripherie ber lagerten sich nun Zellen an diese feinkörnige Intercellularsubstanz, indem an manchen Stellen die Grundsubstanz die sich anlagernde Zelle förmlich umfasste. Ein Theil der Zellen bildete sich nun zu Zwischensubstanz um, indem zunächst das Zellprotoplasma verloren ging, und nur treie Kerne in der Riesenzelle lagen, bis auch diese schliesslich in die Bildung der feinkörnigen Intercellularsubstanz übergingen; ein anderer Theil der Zellen bildete sich zu Saftspalten um, wobei die Vorgänge genau dieselben waren wie beim Schleimgewebe. Diese so gebildete Riesenzelle erschien dann dentlich durchsetzt von einem feinen Kanalwerk; in der Zwischensubstanz lagen die Kerne der Riesenzellen. Zur Bildung solcher Riesenzellen wurden sogar in Mitose begriffene Sarcomzellen verwandt, so dass 
man Bilder antraf, wo in einer Riesenzelle neben normalen ruhenden Kernen sich Kerne mit mitotischer Theilung fanden.

Mit diesem Kapitel kommen wir zum Abschluss mit der Gruppe der Bindesubstanzen und haben gesehen, dass jede derselben, die eine häufiger, die andere seltener, in den Zustand von einer Art Schleimgewebe übergehen kann, wobei aber kein wirklich indifferenter Zustand auftritt, sondern deutlich theils in den Zellen, theils in der Grundsubstanz Annäherungen an den Bau des definitiven Gewebes erhalten bleiben. Wenn wir jetzt zu den Geweben der höheren Ordnung übergehen, so war an den Muskeln ausser den unzweifelhaften Myxombildungen bisher wenig bekannt, was man als einen reinen Vorgang der Rückbildung in Schleimgewebe bezeichnen könnte; bei der Untersuchung des folgenden Falles gelang es mir festzustellen, dass auch das Muskelgewebe einen Status mucosus besitzt.

\section{Fall 12. Myogenes Schleimgewebe an der Kapsel eines Myxoms des 0 berschenkels.}

Herr Dr. Marx sandte aus Erwitte zwei von ihm exstirpirte Myxome vom Oberschenkel eines 56 jäbrigen Mannes, dem an dieser Stelle schon 2weimal ähnliche Tumoren abgetragen worden waren. Die Geschwulst giebt frisch sehr reichliche Fällung von körnigem und fädigem Mucin. Die Zellen enthalten neben grober Körnung sehr vielfach kleine Fettropfen, die Kerne sind aber - wie Härtung auf dem Objectträger, Extraction mit Alkohol und Aether und Färbung zeigt - wohl erhalten. Manche Stellen schimmern im Sonnenlichte gelblich und enthalten so viel Fett in Zellen und Zellverbänden, dass der Tumor als Lipomyxom angesprochen wird.

Um die kugligen Geschwülste zieht sich an einigen Stellen eine dünne Lage quergestreifter Musculatur herum, welche eine Kapsel um die Tumoren bildet. Hiervon werden Stücke in Alcoh. absol. gehärtet und gefärbt mit Alauncarmin-Eosin, mit Pikrocarmin, Saffranin und Entfärbung in Pikrinsäure-Alkohol. Die Manuichfaltigkeit in den Bildern der im Untergange begriffenen Muskelfasern ist so gross, dass man mit 100 Zeichnungen noch nicbt alle Formen erschöpfen würde: wan sieht Muskelbündel, welche in Spindelzellen langsam abschmelzen, solche, welche zahlreiche Kerne im Längsverlaufe der Fibrillen enthalten, andere die im Querverlaufe sich auflösen (vergl. Krösing, Ueber Muskelgewebe). Manche werden feinkörnig, in dew leeren Sarcolemmaschlauch anderer liegen vereinzelte Zellen, die anscheinend von Flüssigkeit umspült gewesen sind. Quergestreifte kernlose Fibrillen werden zu längs- oder zu spiralig gewundenen bindegewebigen Faserbündeln. Zellen lösen sich von den Muskelbündeln ab, und gehen direct in Fettzellenverbände oder. in Bindegewebsbündel über. Abgelöste Zellen 
und ganze Nustselbündel geben direct in Schleimgewebe 3 ber, an anderen Stellen entwickelt sich Schleingewebe aus dem Status fibrosus oder adiposus.

An der Grenze dieser Kapsel zum Tumor finden sich erwachende Kerne in feinlörnigen Grundsubstanz, active Betheiligung des myogenen Schleimund Fasergewebes am Aufbau der Geschwulst ist vicht nachaweisen.

Epikrise: Die durch den Tumor stark gedehnte Musculatur verfällt dem Untergange; das Myosin verschwindet, viele Fasern werden heller und heller, ihre Kerne verblassen, es erfolgt Atrophie. Andere Fasern lösen sich in verschiedener Form in einen zelligen Zustand auf, die Zellen gehen in Faserbündel oder in Fettzellverbände oder in mucinhaltige Grundsubstanz, d. h. Schleimgewebe über.

Am Nervensystem ist, abgesehen von den später zu behandelnden Tumoren eine Reihe von Fällen in den letzten Jahren in den Vordergrund getreten, welche man zwar mit dem Namen der Rankenneurome oder plexiformen Neurome belegt hat, welche aber thatsächlich ganz und garnicht nach Form und Ausbreitung zu den eigentlichen Geschwülsten zu rechnen sind. Diese Ranken, welche aus einem Schleimgewebe zusammengesetzt sind, folgen auf weite Strecken dem Verlauf des Nerven, gehen oft auf zahlreiche Verzweigungen derselben über und bilden ähnlich dem Nabelstrang knotige Auftreibungen, ohne aber jemals weder zusammenhängende selbständig wachsende Geschwulstknoten zu bilden, noch in infiltrativem Wachsthum in die Nachbargewebe einzudringen. Die Bezeichnung als Neurom erweckt die Vorstellung, dass im Wesentlichen ein Neoplasma vorläge, also ein Gewächs, welches aus reichlicher Zelltheilung hervorgegangen wäre. Dass es sich thatsächlich mehr um eine einfache Umbildung von Nervenfasern in Schleimgewebszustände, also um eine Metaplasie in unserem Sinne handelt, soll der nächstfolgende Fall darthun, bei dessen Beschreibung ich genöthigt sein werde, einige Andeutungen über die zellige Umbildung von Nervenfasern zu machen, Beobachtungen, welche an anderer Stelle eingehend beschrieben werden sollen.

4al1 13. Neuroma plexiforme der Temporalgegend, von Prof. Lelferich exstirpirt am 19. Januar 1892 (Fig. 6).

Das Neuroma plexiforme wurde aus der Temporalgegend eines 22jährigen Individuums auf der biesigen chirurgischen Klinik exstirpirt. Die Unter- 
suchung des frisch exstirpirten Präparates ergiebt einen Tumor von ungefähr Faustgrösse, an dem man bei der Palpation deutlich harte, solide, vielfach unter einander verschlungene Stränge durcbfüblen kann. Diese verschlungenen und gewundenen Nerrenstränge liegen in derbem Narbengewebe, so dass es schwer wird, sie aus dem derben Bindegewebe herauszupräpariren. Das die Nervenstränge umgebende Bindegewebe ist vielfach in eine gallertige, durchscheinende Masse umgewandelt, der Nerv selbst hat seine weisse Farbe eingebüsst und eine mehr durchscheinende glasige Färbung angenommen. Das umgebende Gewebe ist zum grössten Theil derbes, straffes Bindegewebe, zum geringsten Theil lockeres, weiches Gewrebe. Aus einem soliden Strang wird nun ein Stück excidirt, dasselbe zerzupft und nach Essigsäurezusatz einer mikroskopischen Untersuchung unterworfen. Neben zablreichen Längszügen von freien Fasern, an denen keine Markscheiden mehr zu erkennen sind, und vielfach wellig verschlungenen, freien Axencylindern findet man das ächte Bild der Mucingerinnung: feinste Fäserchen, die vielfach unter einander anastomosiren, und in deren Verlauf man stellenweise Zellkerne liegen sieht.

Bei der Untersuchung von mit Saffranin gefärbten Schnitten mit schwacher Vergrösserung sieht man in einer schwach graublauen Grundsubstanz zunächst in der Längsrichtung des excidirten Stückes länglich ovale Kerne in parallelen Zügen angeordnet, die fast die ganze Breite des Präparates einnehmen; auf beiden Seiten dieses Theiles tritt die parallele Anordnung vollständig in den Hintergrund, auch nimmt hier die Zahl der Kerne bedeutend $a b$, so dass dadurch die Struktur der Grundsubstanz als eine ziemlich homogene, gleichmässig granblau gefärbte erkennbar wird. Bei Untersuchung mit stärkster Vergrösserung haben die Zellkerne in den zu parallelen Zügen angeordneten Bezirken eine längliche, ovale, spindelförmige, manchmal stäbchenförmige Gestalt, so dass sie den Kernen glatter Muskelfasern nicht unähnlich sehen, sind rosa gefärbt mit deutlich gefärbter Chromatinsubstanz, die namentlich durch ihre intensive Färbung die Kernmembran und die Kernkörperchen hervortreten lässt (Fig. 6 K). Diese Kerne liegen nun zu Reihen angeordnet an und in den Fasern (Fig. 6 F), welche nicht den Fasern eines straffen Bindegewebes gleichen wegen ibres gleichmässig geraden Verlaufs und Mangels jeder welligen Struktur, sondern wobl als Ueberbleibsel früher bestandener nervöser Elemente, als Axencylínder aufzufassen sind (Fig. $6 \mathrm{KA}$ ). Die Fasern sind graublau und gleichmässig gefärbt und lassen an den meisten Stellen des Präparates eine doppelte Contourirung erkennen. Zwischen den Fasern liegen Saftlücken, theils als längs verlaufende Spalten, theils als quer getroffene Lücken erkennbar. Jede Andeutung einer Markscheide oder von Myelintheilen fehlt gänzlich.

Diese parallel verlaufenden Gruppen von Axencylindern werden nun von einander getrennt durch ein Gewebe, welches wesentlich den Typus des Schleimgewebes trägt. In einer theils homogenen, theils feinkörnigen, schwach rosa gefärbten Intercellularsubstanz finden sich Zellkerne, welche intensiver gefärbt sind als die oben beschriebenen Kerne und sich ausserdem von 
diesen durch ihre nehr rundiche Form unterseheiden (Fig. $6 \mathrm{kK}$ ), daneben fiuden sich auch Zellkerne rom Typus der oben beschriebenen. Yon dem Zelprotoplasma um die Kerne herum findet sich nur in einzelnen Fällen eine deutlich als Zellleib anzusprechende rosarothe Färbung, die meisten Kerne liegen frei an Saftspalten oder Saftücken in einew Gewebe, das eine homogene Beschaffenheit hat und won feinsten, vielfach sternförmig angeordneten Fäserchen durchzogen ist (Eig. $6 \mathrm{FG}$ ). Da nun der Kernreichthum dieser schleimigen Substanz als ein nicht unbeträchtlicher zu bezeichnen ist und fast bei jeden Kern seine Beziehung zu Saftspalten nachuweisen ist, so entsteht also eine Substanz, welche äusserst saftreich und nach den verschiedensten Richtungen von Saftspalten durchzogen sein muss. Dieses scbleimige Gowebe enthält nun ausser den Zellen noch einzelne oder in einigen Abständen verlaufende Fasern, welche vielfach Kerne enthalten und leer gewordenen Schwann'schen Scheiden gleichen. Von den sonstigen die markhaltigen Nerven aufbauenden nervösen Bestandtheilen ist nichts wabrzunehmen, an Stelle der Markscheiden ist ein Schleimgewebe getreten, in dem sieb die meisten Zellen zu Saftspalten umgeformt und so ein äusserst saftreiches Gewebe geschaffen haben.

Epikrise: In dem vorliegenden Fall finden sich in dem Verlauf des Nerven nirgends mehr vollentwickelte, markhaltige Nervenfasern, sondern an ihrer Stelle ein Gewebe, welches auf den ersten Blick drei verschiedene Componenten zeigt: 1) zahlreiche kernhaltige Fasern, die parallel verlaufen und unschwer als marklose Nervenfasern erkennbar sind, 2) breite Bindegewebsbündel, welche aber dieselben langen, stäbchenförmigen Kerne bald dichter, bald weitläufiger enthalten, wie sie den marklosen Nervenfasern eigen sind, so dass diese Abschnitte auf das Bestimmteste von gewöhnlichem Bindegewebe unterschieden werden können, 3) Stellen, in welchen ein feinkörniges Schleimgewebe vorhanden ist, in dessen Grundsubstanz man wiederum dieselben langen Nervenkerne verschwinden sieht. Die drei Gewebsarten sind so untermischt, dass bald mehr der Charakter der markhaltigen Nerven, bald mehr der fibröse, bald mehr der mucinöse Theil im Vordergrund steht, aber so mit Sicherheit der nervöse Charakter auch in dem fasrigen und schleimigen Theil erkennbar ist. Ich habe Gelegenheit gehabt, den Fall von Pomorski (dieses Archiv Bd. 111. 1888) und zwei andere Fälle von sogenannten Neuromen mit meinem Präparat zu vergleichen. Bei Pomorski fand sich neben erhaltenen markhaltigen Nervenfasern ein Uebergang zu marklosen bindegewebigen Stellen, bei welchen noch deutlich der Zusammenhang der bereits markfreiea $A b$. 
schnitte mit der Anordnung der Nervenfasern erkennbar ist, so dass man hier die Umbildung der Nervensubstanz in Fasern verfolgen kann. Bei einem zweiten Fall sind nur noch marklose Fasern zu sehen, vielfach unterbrochen von einem weitmaschigen losen Bindegewebe ohne eigentlichen Uebergang zum Schleimgewebe. Es unterscheidet sich dieser Fall vom vorigen dadurch, dass der Umwandlungsprozess schon in ein weiter vorgeschrittenes Stadium eingetreten ist, indem sich keine Markscheiden mehr vorfinden, sondern nur marklose Fasern hervortreten. Ein noch späteres Stadium der Umwandlung zeigt der dritte Fall. Bei diesem zeigen Quer - und Längsschnitte den Verlauf des Nerven, ohne dass irgendwo Myelinsubstanz erhalten wäre; hier sind die Fasern vielmehr aufgelöst in lauter lange schmale Spindelzellen oder wenigstens in Fasern, welche in dichten Abständen lange stäbchenförmige Kerne enthalten, welche in der Nervenscheide zwar dieselbe Beschaffenheit haben, aber mehr Fibrillenbündel zwischen sich lassen. Diese 3 Fälle stehen also in dem Verhältniss, dass sie in aufsteigender Richtung die Umwandlung der nervösen Elemente in eine zellige Substanz zeigen; von einem Schleimgewebe ist nirgends etwas zu finden.

Der Fall von Pomorski hatte dadurch die Aufmerksamkeit auf die Untersuchung der Nerven gerichtet, dass in der Haut der Leiche multiple weiche Fibrome vorhanden gewesen waren, ein Zusammentreffen, auf welches v. Recklinghausen (Ueber die multiplen Fibrome der Haut. Berlin 1882) hingewiesen hat, indem er zugleich aus der eigenartigen Struktur der Mollusken den Schluss zog, dass auch diese Gewächse ihren Ursprung von den Scheiden kleinster Arterien oder Nerven nehmen möchten. Ich kann v. Recklinghausen darin nur beipflichten, dass sowohl das Bindegewebe als das Schleimgewebe, so ähnlich es äusserlich auch gewöhnlichem Bindegewebe sein mag, doch seinen Ursprung aus dem Nervengewebe erkennen lässt, und ich sehe mich daher um so mehr berechtigt, in dem Rankenneurom nicht eine eigentliche Geschwulst durch Bindegewebswucherung entstanden, sondern einen mit Wucherung verbundenen Uebergang der markhaltigen Nervenfasern in fasrige oder schleimige Zustände zu erblicken.

Was für das peripherische Nervensystem die Neurome, d. h. 
Tumoren, welche entstanden sind durch $W$ acherungen und Umbildung der Nervenfasern in homogene, glasige, weiche Geschwulstmassen, sind in dem Centralnervensystem die Gliome. Diese Gesehwulstform, die sich nar in dem Gehirn und Rückenmark, vielleicht noch an einigen Gehirnnerven entwickelt, tritt äusserlich in verschiedenen Modificationen auf: als derbe oder als mar. kige oder als gallertige, schleimige, von der Nachbarschapt nicht deutlich zu trennende Tumoren. Diese letzte Gruppe besteht aus einem weichen, gallertigen, durchscheinenden Gowebe, das makroskopisch grosse Aehnlichkeit mit dem Gewebe ächter Myxome zeigt, mikroskopisch aber solche Verschiedenheiten erkennen lässt, dass ich einen Fall von Gliombildung, den ich untersuchte, glaube hier anreihen zu müssen.

Fall 14. Myxoglioma der rechten Femisphäre oines $42 j$ arhigen Wannes, der an Hemiplegie gelitten hatte (Fig.4).

Nach Eröffnung der Schädelhöhle fällt eine geringe Asymmetrie der Hemisphären auf, indem die rechte ein wenig grösser ist, ais die linke. Beim Durchschneiden durch die rechte Hemisphäre kommt maa in der Gegend unter den Centralwindungen in einen erweichten Heerd ron 5 cro Länge und $4 \mathrm{~cm}$ Höhe, welcher theils aus gallertigem Gewebe, theils aus Blut besteht. Die Umgebung desselben ist auf weite Strecken hin diffus gelblich gefürbt.

Bei mikroskopischer Untersuchung des frischen Objectes sieht man gine Anzahl Zellea, deren Grösse schwan̉̆ ungefähr zwischen der 5 bis lofachen Grösse von rothen Blutkörperchen, die sich ebenfalls in jedem Gesichtsfelde finden, so dass dadurch eine Bestimmung der Grösse der Zellen leicht wird. Diese grossen Zellen haben fast durebweg eine runde Gestalt, einen schwach granulirten bis vollständig bomogenen äusserst zarten Zellleib und einen grossen bläschenförmigen Kern mit deutlich erkennbaren Kernkörperchen. Der Zellleib ist so zart, dass vielfach derselbe schon zerfallen ist und sich nur noch als schwacher Hauch an den Kern erkennen lässt, vielfach sich auch nur freie Kerne finden.

Behufs genauerer Untersuchung werden von den glasig durchscheinenden Stellen Stücke aus dem Tumor excidirt und in Flemming'sche Lösung gebracht und in Alkohol gehärtet, die Eärbung gesebieht mit Saffranin.

Bei der Betrachtung mit schwacher Vergrösserung sieht man in einer hellen homogenen schwach rosa gefärbten Intercellularsubstanz eine grosse Anzahl Zellen in dichter Anordnung, so dass das Bild einew mikroskopischen Bild eines Sarcoms nicht unäbnlich erscheint. Zwiscben den Zellen sieht man rosa gefärbte Fäserchen verlaufen, von denen aber bei schwacher Vergrösserung nicht zu unterscheiden ist, ob es sich um Capillaren oder um Nerven handelt. Auch an diesen Fäserchen sieht man von Strecke zu Strecke 
als rotbe Punkte erscheinende Kerne liegen. Die Anzahl dieser Linien schwankt in verschiedenen Präparaten erheblich, in manchen fuden sich nur sehr vereinzelt solche scharfen Füserchen, in manchen dagegen liegen diese Linien dicht zusammen und anastomosiren theilweise mit einander, so dass an einigen Stellen ein gewisses Maschenwerk entsteht.

Bei der Betrachtung mit stärkster Vergrösserung haben die Zellen einen schönen grossen runden bläschenförmigen Kern mit deutlicher Kernmembran und Kernkörperchen (Fig. $4 \mathrm{~K}$ ). Diese schön rosa gefärbten Kerne sind umgeben von einem ganz zarten Zelleib, der entweder bell durchscheinend oder schwach grau gefärbt ist. Dieser Zelleib stebt nun in directer Verbindung mit einem Faserwerk von feinsten. Fasern, so dass es den Eindruck macht, als $o b$ in den Fäserchen die Zellen lägen (Fig. $Z F$ ). Es wird dadurch gewissermaassen das ganze Präparat gebildet aus einem feinsten Netzwerk, in dessen Fasern Zellen liegen. An zahlreichen Stellen verschwindet der Zellleib vollständig und es ist dann der Kern direct von einer sternförmigen Figur umgeben, deren Fasern sich in directe Verbindung setzen mit den Fasern von anderen Zellen. Das Faserwerk wird an manchen Stellen so undeutlich, dass man eine gewisse Faserung wohl noch erkennen kann, aber die Intercellularsubstanz mehr eine feinkörnige Bescbaffenheit annimmt.

Unterbrochen wird dieses ziemlich gleichmässige Bild hier und da von Blutgefässen, welche theils auf dem Querschnitt getroffen sind und in ihrem Lumen nocb rothe Blutkörperchen erkennen lassen, theils auf dem Längsschnitt, so dass man in den Wandungen schöne längliche ovale Kerne liegen sieht, die durch ihre Grösse sich von den Blutgefässkernen, wie man sie sonst anzutreffen pflegt, wesentlich unterscheiden (Fig. 4 B).

Neben den Blutgefässen finden sich hier und da Nervenfasern, deren normaler histologischer Bau meist eine wesentliche Veränderung erfahren hat. Man erkennt nehmlich an den markbaltigen Nerven nur hier und da Andeutungen der Markscheiden als belle durchscheinende unregelmässige Figuren, an den Theilen, wo die Markscheide fehlt, finden sich statt derselben Kerne, welche den oben beschriebenen Kernen gleichen und den Typus der Kerne der Endothelien haben. Diese Kerne steben nun vielfach schon mit der umgebenden $Z$ wischensubstanz in Zusammenhang, so dass dann ein Axencylinder umgeben ist von Zellen, welche theilweise schon in die netzförmige Anordnung der Intercellularsubstanz eingetreten sind, und nur der Axencylinder noch andeutet, dass es sich um Gewebe von markhaltigen Nerven handelt. Schwieriger wird die Erkennung der Nerven noch da, wo schon die Markscheiden in Zellen umgewandelt sind, und wo auch schon der Axencylinder sich in Zellen umzuwandeln anfängt. Man trifft dann Bilder, wo die Markscheide eines Nerven voliständig zellig geworden ist, ebenso theilweise der Axencylinder, so dass man nur zwischen in Reihen liegenden ovalen Kernen doppelt contourirte Spuren des Axencylinders antrifft. Allwäblich verschwindet auch die letzte Andeutung des Axencylinders, und nur die Anordnung der Zellen lässt vermuthen, dass sich hier einmal ein markhaltiger Nerv befunden hat, der jetzt zellig geworden ist. 
Epikrise: Das Gewebo des gallertigen Glioms, die grossen rundea Zellen mit den grossen runden bläschenförmigen Kernen ist hervorgegangen aus Neuroglia und aus den markhaltigen Nerven. Die Umwandlung der Nervenfasern (Markscheiden und Axencylinder) geschieht auch hier so, dass zunächst die Markscheiden zellig werden, $d . h$. dass die Zellen, aus denen sich einmal bei der Entwickelung die Markscheiden gebildet haben, hier bei pathologischen Vorgängen wieder erwachen, und sich in die verschiedenen fasrigen, netzförmigen und körnigen Formen der Neuroglia umwandeln, wobei eine besondere Art von schleimiger Grundsubstanz aus umgebildeten und gewucherten Zellen hervorgeht.

Sowohl das Neurom (Fall 13), als das Gliom (Fall 14) zeigen makroskopisch dieselbe gallertige, glasig durchscheinende Beschaffenheit, und doch zeigt sich, dass die Struktur des Glioms eine wesentlich andere ist wie die des Neuromyxoms. Es fehlt in dem Gliom die homogene Grundsubstanz mit den Saftspalten, es besteht diese schleimige Masse des Glioms im Wesentlichen aus grossen runden Zellen, $z$ wischen denen ein feines Gitterwerk ausgespannt ist, in dem sich eine durchscheinende, ungefärbte Grundsubstanz mit Kernresten im Schlummerzustand befindet; an keiner Stelle findet sich ein Bezirk, der nưr annähernd dem mesodermalen Myxomgewebe gleicht. Es muss sich also in dem centralen Nervensystem um andere Zellen als im peripherischen handeln, so dass man das Verhältniss so ausdrücken kann, dass sich das Neuromyxom zu einem peripherischen Nerven wie das Glioma mucosum zu einem centralen Nerven verhält.

Typische Beispiele für den Status mucosus des centralen Nervengewebes bilden die zuweilen geschwulstartigen, gallertigen Ependymwucherungen der Gehirnventrikel bei chronischem Hydrocephalus internus.

Eine Zusammensetzung des Centralnervensystems aus nervösen Elementen und Bindesubstanz erkennen wir daher ebenso wenig an als wir die Nervenscheide der peripherischen Nerven für definitives Bindegewebe halten.

Alle diese Beschreibungen lehren, dass es eine Einheit von Tela mucosa nicht giebt, dass das Schleimgewebe vielmehr eine Vielheit, ein Aequivalent der verschiedenen Bindesubstanzen der Muskeln und des peripherischen und centralen Nervensystems ist. 
Es giebt eben kein „indifferentes Schleimgewebe" eben so wenig als es ein „indifferentes Fasergewebe" giebt.

Nachdem ich nun aber die Entstehung und den Bau aller dieser Modificationen des Schleingewebes beschrieben habe, so komme ich nun an die Erörterung des "falschen Schleimgewebes", worunter ich das ödematöse Bindegewebe und Fettgewebe verstehe; ich behandle dabei zunächst das passive und danach das active Oedem.

\section{Fall XV. Subcutanes ödematöses Gewebe bei einem Fall von Herzfehler.}

Das ödematöse subcutane Bindegewebe und Fettgewebe stammt von einem an einem Herzfehler zu Grunde gegangenen 22jährigen Mann.

Mikroskopisch sieht man, dass im Bindegewebe die Fasern durch die ödematöse Flüssigkeit aus einauder gedrängt sind, sowohl in diesen Bezirken wie anch in dem Bindegewebe um die Gefässe herum fehlt jeder Kern, nur hin und wieder, aber nur sehr vereinzelt, sieht man grosse runde Kerne, die theilweise Vacuolen enthalten. Die Kerne der Gefässwandungen und der Capillaren sind deutlich erkennbar als schöne roth gefärbte längliche Kerne. In den den ödematösen Bindegewebsbezirken fern liegenden Fettkörpern erkennt man schöne deutlich roth gefärbte erwachte Kerne. In dem von ödematösem Bindegewebe umgebenen Fettgewebe giebt es Bezirke, wo die an den Fettzellverbänden etwa erwachten Schlummerzellen wieder vollständig verschwunden sind, so dass die Membranen vollständig kernlos, meist auch durch ödematöse Flüssigkeit aus einander gedrängt neben einander liegen. Leukocyten oder Saftkanäle im Bindegewebe sind nicbt wahrzunehmen.

Epikrise: Das vorliegende Präparat zeigt in deatlicher Weise, wie sich in den einzelnen Stadien des passiven Oedems die Zellen des Bindegewebes und Fettgewebes verhalten. In den Theilen des Bindegewebes und Fettgewebes, an welchen noch eine Steigerung in der Ansammlung der Oedemflüssigkeit stattfindet, erwachen die schlummernden Zellen des Bindegewebes und Fettgewebes. Man trifft dann an diesen Stellen zahllose Kerne, welche einerseits sowohl an den Bindegewebsfibrillen, wie in denselben liegen; theils in den Membranen der Fettzellenverbände auftauchen und diese wie ein Kranz von Kernen umgeben. Hat nun schliesslich das Oedem den höchsten Grad erreicht, und findet kein never Zufluss, sondern eine Stagnation statt, so erhalten die erwachten Kerne keine Nährflüssigkeit mehr, so sind sie gezwungen sich aufzulösen; daher kommt es, dass an den Stellen des Gewebes, wo eine Stagnation stattge-

Arehiv f, pathol. Anat. Bd.129. Hft. 3 . 
funden hat, man gar keine Kerne trifft, vielleicht nur einige ganz blass gefärbte mit deutlichen Vacuolen, was stets auf einen regressiven Vorgang hindeutet, Beim Fettgewebe, das dem ödematösen Bindegewebe angrenzt, sieht man dieselben Vorgänge: dort, wo das Oedem schon länger eingewirkt hat, sind die Fettzellenverbände aus einander gedrängt, kernlos, und zeigen verschiedene Grösse, was vielleicht als eine beginnende Nekrose aufzufassen ist. In den ferner liegenden Bezirken sind die erwachten Kerne der Fettzellenverbände wenigstens noch angedeutet oder schwächer gefärbt, in den Bezirken, wo das Oedem erst auf das Fettgewebe einzuwirken beginnt, sind die Kerne erwacht und als solche schön deutlich erkennbar.

Der Unterschied dieser Bilder von denen, welche wir im ersten Abschnitte als Schleimgewebe beschrieben haben, ist ein ganz wesentlicher; dort Uebergang von Zellen in mucinöse Grundsubstanz, Capillaren und Saftkanäle, hier Erwachen von Kernen und Zellen und Untergang durch Auflösung derselben im Oedemwasser.

\section{Fall 16. Oedematöse Narbe eines wegen Coxitis operirten $10 j$ ährigen Knaben.}

Das Präparat stammt von einem 10jährigen Knaben, der auf der hiesigen chirurgischen Abtheilung an Coxitis und multiplen Gelenkeiterungen zu Grunde gegangen ist. Unterbalb des rechten Trochanter ist eine ödematöse Narbe von etwa $7 \mathrm{~cm}$ Länge, eine gleiche vorne medial oben am rechton. Oberschenkel. Es wird aus dieser Narbe ein Stück excidirt, wobei eine Menge Oedemflüssigkeit ausfliesst and das excidirte Stück theilweise collabirt. Das Stück wird in Flemming'sche Lösung gelegt, in Alkohol gehärtet und mit Saffranin gefärbt.

Bei Betrachtung mit schwacher Vergrösserung sieht man schon, wie die graublau gefärbten Faserzüge der bindegewebigen Narbe durch die Oedemflüssigkeit aus einander gedrängt sind, so dass gewissermaassen ein Netzwerk von Fasern entsteht, in denen man als feinste längliche Figuren Kerne erkennen kann. Dieser fasrige Bau der Narbe wird stellenweise unterbrochen von Blutgefässen, um welche herum, jedoch nur in näcbster Umgebung sich Anbäufungen von Kernen finden, die Zellen angebören, die durch ihre intensivere Färbung mit den übrigen Kernen lebhaft contrastiren. Genauere Einzelheiten lassen sich erst bei der Anwendung von stärkster Vergrösserung erkennen. Man siebt alsdann, wie die fasrigen Bindegewebszüge aus einander gedrängt sind, so dass ibr normaler paralleler Verlauf verschwindet und mehr ein feines Netzwerk ron gedrängten welligen Fasern entsteht. Die fasrige Struktur dieser Bindegewebszüge ist an zahlreichen Stellen so zart und fein, dass man den Eindruck gewinnt, als ob es sich nicht um 
straffes Narbengewebe, sondern um ein weiches dem Schleimgewebe ähnliches Gewebe handelt. In und an diesen feinen Bündeln liegen nun Kerne vom Endotheltypus mit schwach rosa gefärbter Chromatinsubstanz und einem oder mehreren bläschenförmigen Kernkörperchen. Diese Kerne lassen nun meist keinen deutlichen Zeilleib mehr erkennen, sondern sind vielfach als Knotenpunkte aufzufassen, von denen aus theilweise in radiärer Richtung die feinen Fibrillen ausgehen, die wiederum nicht neben einander liegen, sondern in gewissen Abständen aus einander gedrängt sind. An manchen Stellen ist die feine Faserung um die Kerne berum so undeutlich, dass man von einer Faserung kaum noch reden kann, sondern die Intercellularsubstanz mehr feinkörnig geworden ist. Man trifft dann manche Kerne, die auf der einen Seite von feinsten meist radiären Fasern, auf der anderen Seite mehr feinkörnig geworden ist. Dass diese Kerne Zellen angehört haben, welche als ächte Gewebszellen aufzufassen sind, beweisen an gewissen Stellen sternförmige Zellen wit endothelartigem Kern, deren sternförmige Fortsätze in $\mathrm{Fa}$ sern übergehen. In manchen Fasern finden sich auch spindelförmige Bindegewebszellen mit erkennbarem Zellleib und endothelartigem Kern.

Die Kerne der Zellen, welche sich in der Nähe der Blutgefässe finden, sind meist rund, bläschenförmig, mit stark gefärbter Chromatinsubstanz; von dem Zellleib ist nur an wenigen Stellen als heller schmaler Saum etwas wahrzunehmen. An einigen Zellen finden sich Pigmentkörner um den Kern herum, um andere Kerne wiederum findet sich eine feinkörnige Zellsubstanz, welche in radiäre feinste Fäserchen sich auflöst.

Epikrise: Die Vorgänge sind hier im Wesentlichen dieselben wie beim vorigen Fall. Es handelt sich um einen schlecht genährten, durch chronische Gelenkeiterung äusserst erschöpften Knaben, dessen Herzmusculatur durch die allgemeine schlechte Ernährung so schwach geworden ist, dass sie nicht mehr im Stande ist, die Blutmenge durch die Körper zu treiben. Es kommt in Folge dessen zu Staungen, namentlich zunächst an den abhängigen Theilen des Körpers, an den unteren Extremitäten. Auch die Narbe, die sich in der Gegend des rechten Trochanter befindet, ist von diesem Oedem ergriffen; mikroskopisch zeigt sich an ihr, dass die sonst derben Faserzüge des Narbengewebes so stark aus einander gedrängt sind, dass die Fasern theilweise eine feinkörnige Beschaffenheit angenommen haben. Das Oedem ist am stärksten in der Nähe der Gefässe, wo die Maschen des Gewebes auf's Aeusserste aus einander gedrängt sind. Ganz verschieden sind diese Bilder von denen des Schleimgewebes; während man bei den letzteren einen Uebergang der Zellen in Grundsubstanz und Saftkanälchen Schritt für Schritt verfolgen 
konnte, ist hier nichts von derartigen Prozessen wahrzunehmen. Die Zellen, die bei Beginn des Oedems erwacht sind, sind entweder aufgelöst, oder schon längst wieder in den Schlummerzustand übergegangen, nirgends finden sich Kerne, welche als erwachend angesprochen werden können; es beweist dies eben, dass das Oedem schon lange Zeit bestanden haben muss, und es sich hier um abgelaufene Prozesse handelt.

Fall 17. Oedem, erzengt an einem Kaninchenoly durch eine l2stündige Ligatur, 18 Stuaden nach Rnternung der Ligatur wird das oedem untersucht.

Zum Zwecke der Untersuchung von ödematösem Bindegewebe, wird einem gesunden Kaninchen ein gewisser Bezirk des rechten Obres sorgfältig rasirt, dann abgebunden, die Ligatur 12 Stunden liegen gelassen. Sehon während der 12stündigen Dauer stellt sich ein mässiges Oedem ein, welches wächst und sich vergrössert, nachdem nach Verlauf der 12 Stunden die Ligatur gelöst wird. Nachdem nach gelöster Ligatur 18 Stunden verflossen sind, wird aus dem ödematösen Ohr ein Stück excidirt und dieses sofort in Wlemming'sche Lösung gebracht, entwässert und in Alkohol gehärtet.

Auf einem mikroskopischen Bild zeigen sich bei schwacher Vergrösseruag auf einem mattrosa gefärbten Untergrunde an verschiedenen Stellen Zellanbäufungen, besonders in der Umgebung der Gefässe. Zwischen den zellreichen Bezirken finden sich sowohl vollständig zellfreie Bezirke, als auch solche, wo die Zellen nur vereinzelt liegen. Die Untersuchnng mit stärkster Vergrösserung zeigt, dass es sich um ganz complicirte Vorgänge handelt. Die Zellanhäufungen um die Gefässe herum erweisen sich als aus dem Blute stammende Leukocyten: es sind runde Zellen mit mebreren deutlichen Kernen, die in verscbiedener Anordnung liegen und sich bald zu S-förmigen bald hufeisenförmigen Figuren gruppirt haben; je weiter yon den Gefässen, um so seltener werden sie.

Die Grundsubstanz zejgt eine schöne fibrilläre Struktur, nur sind die Fibrillen nicht neben einander liegend zu Bündeln formirt, sondern durch die Oedemflüssigkeit aus einander gedrängt, so dass das Präparat an manchen Stellen wie macerirt aussieht, da man fast jede Fibrille isolirt wahrnehmen kann. In der fibrillären Grundsubstanz finden sich zahlreiche Saftspalten, welche auf das Aeusserste ausgedehnt sind, und theils wandständige Kerne haben, theils kernlose unregelmässig geformte Röhren bilden, in der Umgebung dieser kernlosen Spalten finden sich keine Gewebszellkerne, der ganze Bezirk ist kemlos, nur einige Leukocyten trifft man. Neben diesen vollständig kernlosen Bezirken finden sich Bezirke, in denen eine grosse Zahl Gewebskerne erwacht sind. Die $Z$ wischensubstanz zeigt auch hier schon kleine Spalten, an deren Wandungen man schöne Epithelkerne wahrnimmt, ebenso zeigen die Gewebsfasern längliche Kerne; Lenkocyten sind nur sehr vereinzelt vorbanden. Diese letzten Berirke finden sich meist nahe der Oberfäche. 
Epikrise: Ganz complicirte Vorgänge spielen sich am vorliegenden Präparat ab. Das Oedem, das schon während der Ligatur sich entwickelte, ist als einfaches Stauungsödem aufzufassen; erst später als die Ligatur gelöst wurde, entwickelte sich nach und nach ein entzündliches Oedem auf dem Boden des passiven. Das Oedem hat nun die Maschen des Gewebes aus einander gedrängt und die Saftspalten bis auf's Aeusserste erweitert, dadurch ist es schliesslich zu vollständig nekrotischen Bezirken gekommen, wo sich weder im Gewebe noch in den Saftspalten Kerne finden; selbst die fixen Bindegewebszellen, die man sonst in den Kanälen antrifft, sind nicht mehr vorhanden; ob sie einfach zu Grunde gegangen oder ausgewandert sind, ist nicht mehr zu entscheiden. Wahrscheinlich handelt es sich um das erstere, um einen regressiven Prozess, da man sonst in der Umgebung der Saftspalten jedenfalls im Gewebe solche Zellen antreffen würde. Die nekrotischen Bezirke sind die Folge der Staung, der stagnirende Gewebssaft giebt in seinem Höhestadium, wo das Oedem die grösste Ausdehnung erreicht hat, also keine Flüssigkeit mehr ausströmen kann, keine geeignete Nährflüssigkeit für die Zellen mehr ab, so dass diese zu Grunde gehen; man trifft dennoch hier und da blasse schwach gefärbte Kerne in der Intercellularsubstanz. Anders verhält es sich in den Bezirken, wo das Oedem erst seinen Anfang nimmt und die Maschen erst wenig aus einander gedrängt sind. Durch den hier neu hinzuströmenden Gewebssaft erwachen die schlummernden Zellen sowohl in den Fasern wie an den Spalten, so dass dann Bilder entstehen, wie sie oben beschrieben sind, wo zahllose Kerne in der Nähe der Oberfläche erwacht sind. $O b$ nun diese Zellen sich später einfach zurückbilden oder regressive Vorgänge durchmachen und zerfallen, dafür bietet das Präparat keine Anhaltspunkte.

Achnliche Versuche mit und ohne Bakterieninfection sind im pathologischen Institut von Ed. Richter gemacht, und in seiner Preisarbeit „Ueber den Antheil entzündlicher Prozesse an der Entstehung und Ausbreitung der Spontangangrän" beschriebeu worden. Die Mittheilung dieses einzelnen Präparates hat also nur den $Z$ weck zu zeigen, dass diese Art der Abschnürung, welche von Cohnheim, Samuel u. A. wegen des typischen Auftretens der Cardinalsymptome von Tumor rubor dolor 
calor bevorzugt worden ist, um die Entzündungslehre darau? zu begründen, histologisch höchst complicirte Gewebsveränderungen aufweist, welche von dem Bilde eines Furunkels erheblich verschieden ist. Aber auch dieses aus passiver und activer Periode zusammengesetzte Oedem liefert kein Schleimgewebe.

Fall 18. Entzündliches Oedem einer Paraphimose.

Bei dem Stud. med. A. M. hatte sich eine Paraphimose spontan entwickelt, das Präputium schwoll allmählich wäbiend der folgenden 3 Tage nach der Entstehung so an und wurde so schmerahaft, dass sicb Patient zu der Incision entschloss.

Das ödematöse Gewebe wurde 3 Tage nach dem Fntstehen exstirpirt und sofort in Flemming'sche Lösung eingelegt.

Schon bei Betracbtung mit schwacher Vergrösserung bietet sich ein sebr mannichfaltiges Bild dar. Auf der einen Seite des mikroskopischen Schnittes findet sich eine dichte Zellanhäufung, wie man sie bei einer eitrigen Schmelzung des Bindegewebes findet. Diese Anhäufung von Zellen ist nun in diesen zellenreichen Partien keine gleichmässige, sondern an manchen Stellen lassen die Zellen deutliche $Z$ wischensubstanz $z$ wischen sich, die theils als horogen durebsebeinend sich erweist, theils von scharfen intensiv rothen Fasern durchzogen ist, wodurch ein feines Maschenwerk entsteht, in dessen Maschen die Zellen liegen. Die Wandungen der in diesem Bezirk liegenden Blutgefässe sind so dicht mit Zellen angefullt, dass sie fast nur aus Zellen zu bestehen scheinen. In der Umgebung dieser Blutgefässe ist die sonst homogen durchscheinende Intercellularsubstanz leicht gelblich tingirt. Neben diesen zellenieichen Bezirken finden sich nun alle Abstufungen bis zu vollsiändig zellenlosen Bezirken. Die Mitte nehmen Bezirke ein, wo in einer homogenen Interceliularsubstanz Zellen liegen, theils mehr zerstreut, theils zu kleineren Gruppen vereinigt. Die vollständig zelllosen Bezirke, die durch ibren vollständigen Zellmangel nekrotischen Theilen ähnlich werden, finden sich namentlich in der nächsten Ungebung uo die Blutgefässe herum, und sind vielfach durch Blutfarbstoff gelblich tingirt. Bei der Betracbtung mit stärkster Yergrössemng zeigen sich zunächst in den zellenreichen Bezirken folgende Einzelheiten. Der Bezirk, der sich bei scbwacher Vergrösserung als einfache dichte Zellanhäufung zeigte, erweist sich als das Bild einer Bindegewebseinschmelzung, wie sie sich bei der Eiterbildung findet. Zunächst lässt sich bier noch klar die Abstammung dieser Zellen aus Bindegewebe erkennen. Es finden sich nebmlich diese Zellen, die in der Mehraahl kreisrunde Form, einen hellen protoplasmatischen nicht granulirten Leib und meist gekerbte Kerne haben, insofern als zu den Fasern gebörig, als sie direct in dem Verlauf der Fasern liegen, bei manchen, wo der Zellleib nich hell, sondern gelblich tingirt ist, versehwindet daan die kreisrunde Zellform, man sieht dann nur, wie in einer spindelförmigen Anschwellung der Fasern ein oder mehrere Kerne liegen. Neben diesen Zellen, dio durch 
ibre gekerbten oder kleeblattähnlichen Rerne den Leukocyten gleichen, finden sich Zellen mit Kernen von deutlich endothelialem Charakter; auch sie erweisen sich als in den Bündeln gelegen. An den meisten Stellen finden sich nun gar keine Bindegewebsfasern mehr vor, sondern nur einfache Zellanhäufungen; da die Zellen in der Mehrzahl einen vollständig hellen kreisrunden Leib haben, und dicht an einander gelagert sind, so gewinnt man den Eindruck, als ob in bellen kreisrunden Lacunen entweder Kerne von Endothelkerntypus oder Leukocytentypus, letztere meist in der Mehrzahl, liegen; die hellen Lacunen sind die hellen Zellleiber. Die Zellen liegen vielfach noch in Reihen angeordnet, und zeigen auch durch diese Anordnung ihre Entstehung aus Fasern an. Was nun die Blutgefässe in diesem Bezirk betrifft, so zeigt sich, dass die ganze Gefässwand aus lauter Zellen mit meist länglichem bläschenförmigem Kern besteht, welche aus einander gedrängt erscheinen und Lücken $\mathrm{zwischen}$ sich lassen. Die fasrige bindegewebige Struktur der Adventitia ist vollständig verwischt, nur an einigen wenigen Stellen finden sich noch einzelne Fasern, die meisten Fasern sind wieder zellig geworden, die Zellen aus einander gedrängt, so dass man deutlich den Eindruck des Oedems erhält; die Zwischenbezirbe zwischen den Zellen, die sich bei schwacher Vergrösserung als gelblich tingirt erwiesen, sind mit ausgetretenen rothen Blutkörperchen angefüllt.

An manchen Stellen finden sich nun feinste Netze von elastischen Fasern, in deren Knotenpunkten und in deren Verlauf man vielfach Kerne trifft vom Typus der oben beschriebenen leukocytenäbnlichen Art. An manchen, namentlich an den Knotenpunkten finden sich in den Fasern liegend schöne Zellen mit hellem rundem protoplaswatischem Zellkörper und meist mebreren Kernen. Vielfach haben diese Zellen nun nicht ibre vollständige Ausbildung erlangt, sondern man sieht, wie in der Faser an einer Stelle sich nur zum Theil der belle homogene Zellleib findet, der Rest des Zellleibes ist nicht $\mathrm{zu}$ unterscheiden und $\mathrm{zu}$ trenuen von der elastischen Faser, sondern geht in kleinste rothe verästelte Fortsätze aus.

In den Bezirken nun, die bei der Betrachtung mit scbwacher Vergrösserung als Mittelgied von der zellreichen zur zelllosen Schicht beschrieben wurde, findet sich ein durch Oedemflüssigkeit aus einander gedrängtes Gewebe. An den Fasern liegen Zellen vom Typus der Gewebszellen, die meist schön gefärbt sind, und sich dadurch als lebende Zellen von einer anderen Gruppe unterscheiden, deren Zellen mehr diffus, theilweise auch blasser gefärbt sind. Diese letzteren Zellen können nun alle Stufen der Färbung mitwachen, bis zuw vollständigen Abblassen, oder sie zerbröckeln vollständig, so dass man schliesslich nur nouh Zelltrümmer antrifft. So entstehen denn schliesslich vollständig zellarme Bezirke, wo sich in einer meist feinkörnigen, aus Detritus bestehenden Substanz nur böcbstens noch schwache Andeutungen von Zellen oder Zellkernbröckel vorfinden. Diese letzten Bezirke finden sich namentlich in der Näbe der Gefässe; schon die Adventitia lässt keine deutliche bindegewebige Struktur mehr erkennen, sondern ist zellig geworden, die Zellen sind weit aus einander gedrängt, die Fasern, die noch vorhanden sind, gehen in eine feinkörnige Masse über. 
Dort wo die Saftspalten, die sich in normaler Weise im Bindegewebo finden, aus einander gedrängt sind, durch mässige Nengen Flüssigkeit, giebt es schöne Bilder, in denen Bindegewebsfasern als isolirt verlaufende lockige Bündel erscheinen, in deren Verlauf schöne längliche Kerne eingereiht siud. Dort, wo die Saftspalten bis auf das Aeusserste erweitert - diese Stellen gehören den zellenlosen Bezirken an - finden sich höchstens nur noch Uoberbleibsel ron Zellen, meist sind die Zellen an den Wandungen der Saftspalten vollständig verschwunden.

Epikrise: Die Vorgänge, die sich an dem ödematösen Unterhautzellgewebe bei einer 3 Tage bestehenden Paraphimose abspielen, sind ziemlich complicirte. Zunächst sind die Stellen, in denen sich eine dichte Zellanhäufung findet, als die am weitesten vorgeschrittenen Stadien der Entzündung aufzufassen: es sind nehmlich hier die Bindegewebsfasern im Begriff, eine eitrige Schmelzung einzugehen. Die Zellen, die sich aus den Fasern bilden, sind wegen ihrer Lage innerhalb und nicht zwischen den Bündeln, wegen ihrer grossentheils endothelartigen Kerne und der sie umgebenden gitterartigen Reste von Grundsubstanz als von den ausgewanderten Leukocyten verschiedenartig beschrieben worden, da polynucleäre Zellen nicht nur in den farblosen Elementen des Blutes, sondern auch als abortive Formen bei der Faserumbildung und als Degenerationsformen der freien Gewebszellen vorkommen. Diese eitrige Schmelzung ist nun an einigen Stellen schon so weit vorgeschritten, dass sich gar keine Bindegewebsfasern mehr finden, sondern nur Zellen, welche die umgewandelten Gewebszellen darstellen; dass diese Zellen aus umgewandeiten Fasern hervorgegangen sind, beweist noch ihre vielfach reihenförmige Anordnung. An der eitrigen Schmelzung betheiligen sich auch elastische Fasern, wobei man deutlich die Umwandlung in Zellen verfolgen kann; an manchen Stellen ist diese Umwandlung so schnell vor sich gegangen, dass die Zellen nicht Zeit gehabt haben, sich vollständig fertig zu bilden; man trifft dann Zellen, welche theilweise schon protoplasmatischen Leib erkennen lassen, theilweise aber noch in Fasern übergehen. In den ödematösen Bezirken sind durch die Einwirkung des Oedems zunächst die Zellen erwacht, je mehr aber das Oedem wächst, um so weniger Nährmaterial erhalten die Zellen, sie gehen zu Grunde, es entstehen dann vollständig nekrotische zellenarme Bezirke, in denen man 


\section{1}

nur die auf's Aeusserste aus einander gedrängten Fasern bemerkt; selbst die Wand der Gefässe hat sich an dem Oedem betheiligt, die Maschen sind aus einander gedrängt, was an manchen Stellen so weit gegangen ist, dass durch die so entstandenen Lücken rothe Blutkörperchen durchgetreten sind und auf diese Weise Hämorrhagien im Gewebe entstanden sind.

Auch hier hat sich ein Befund ergeben, der von dem Schleimgewebe ganz principiell verschieden ist.

Die wichtigste Gruppe pathologischer Vorgänge, bei welcher Schleimgewebe auftritt, bilden die Geschwülste.

\section{Fall 19. Nasenpolyp, von Prof. Strübing exstirpirt.}

Es bandelt sich um einen Nasenpolyp von ungefähr Erbsengrösse, der von Prof. Strübing exstirpirt und sofort in Flemming'scher Lösung fixirt und in Alkohol gehärtet wurde. Nach Färbung mit Saffranin zeigte sich bei scbwacher Vergrösserung, dass der Tumor überzogen wird von einem mehrfach geschichteten Cylinderepithel, das nur an einigen Stellen durch den Härtungsprozess verloren gegangen ist; diese Epithellage enthält an manchen Stellen einen schmalen Saum eines geronnenen schleimigen Materials. Der Grundstock des Tumors bestebt aus einer homogenen gelblichrosa gefärbten Grundsubstanz, die durch gewisse Spalten in Bezirke getheilt wird; in dieser Grundsubstanz treten als rothe Pünktchen Kerne anf, die sehr zerstrent liegen, und nur in der Nähe der Gefässe zu grösseren Gruppen angeordnet sind. Unterhalb der Epithellage sind ebenfalls die Kerne dichter gelagert als in centralen Theilen des Tumors. Hin und wieder wird der gleichmässige homogene Bau der Grundsubstanz unterbrochen durch mit Cylinderepithel angekleidete Drüsenlumina. Bei Betrachtung mit stärkster Vergrösserung fallen zunächst verschiedene Zellformen auf: Die erste und zugleich grösste, allerdings in der Minderzahl vorhandene Zellart zeigt den Typus der Mastzellen; diese Zellen haben die Form von Rundzellen, einen intensiv roth gefärbten stark granulirten Kern, obne dass Kernkörperchen sicbtbar sind, und einen schmalen bellen Protoplasmasaum. Sie liegen durchweg in Saftspalten vollständig frei, ohne sich also irgendwie an der Bildung der Saftkanäle oder der Intercellularsubstanz zu betheiligen. Neben diesem Zelltypus trifft man als zweite Zellform Kerne vom Endothelkerntypus, die sich am Aufbau des fibrillären Bindegemebes betheiligen, das den Grundstock des Tumors ausmacht. Hier liegen die länglicb-ovalen Kerne mit deutlich differenzirter Kernmembran und Kernkörperchen und schwach rosa gefärbter Chromatinsubstanz meist im Verlauf der Bindegewebsbündel, theilweise auch an denselben. Dass die Fasern des Bindegewebes direct aus diesen Zellen hervorgehen, lässt sich an einigen Stellen deutlich verfolgen, an denen man Zellen trifft mit den Endothelkernen, wo auf der einen Seite sich das Proto- 


\section{2}

plasma schon zu einem lockigen Bündel umgeformt hat, während aw der anderen Seite das Protoplasma noch mehr die Gestalt der Rundzelle bewahrt hat, daneben findet man solche, wo die Zellen schon spindelig geworden sind, wo also der Kern dann in körnigem oder fibrillärem Zellenleibe liegt, der zum Faserbündel wird. Als dritter Zelltypus tritt eine ganz kleine Zellart auf, an der meist nur noch der intensiv rothe Zellkern zu erkennen ist, dagegen der Zellleib nach $\mathrm{z}$ wei Richtungen hin andere Veränderungen eingegangen hat. Hinmal trifft man noch vollständig erbaltene Zellen in der Intercellularsubstanz liegen, die meisten Zellen baben jedoch ihren Zellleib verloren, man siebt nur freie Keme, die anfangs noch von einem scbwach roth gefärbten Hof umgeben sind, der sich deutlich von der Intercellularsubstanz abhebt. Dieser Hof wird jedoch allmählich immer mebr der Intercellularsubstanz gleich, bis er sebliesslicb nicht von der umgebenden Intercellularsubstanz zu differenziren ist. An anderen ist dann auch der Kern blasser, und verschwindet schliesslich ganz. Die gesammte Zelle ist dann in die Schlummerform ïbergegangen. Kinen anderen und weit grösseren Theil der Kerne dieser Zellen vom dritten Typus trifft man an der Wand von langen Spalträumen, welche die Grundsubstanz durchziehen, oder an der Wand von kreisrunden Vacuolen, welche wechselnde Grösse haben können. Die Kerne an den Wandungen dieser Spalten sind von wechselnder Färbbarkeit, die meisten sind schön gefärbt, an manchen sieht man jedoch nur noch einen blassen rothen Schimmer, bis auch dieser verschwindet.

Epikrise: An diesen Schleimpolypen der Nase lässt sich fast Schritt für Schritt die Umwandlung der Zellen in Intercellularsubstanz verfolgen, und damit widerlegen, dass die Intercellularsubstanz nur ein Abscheidungsprodukt der Zellen ist. Was zunächst die grossen Zellen betrifft, so lässt sich über ihre Genese nichts sagen, vielleicht sind sie als die permanenten Zellen des Schleimgewebes aufzufassen. Die kleinere Zellform dient wesentlich zum Aufbau der Grundsubstanz, indem sich ein Theil direct in Grundsubstanz umbildet, was allerdings nur an wenigen Stellen noch in seiner ganzen Vollständigkeit zu verfolgen, in den meisten Stellen schon längst abgelaufen ist, Der Vebergang eines Theiles der Zellen in die Schlummerform ist immer der primäre, der Rest der Zellen, welche zur Bildung der Saftspalten gebraucht werden, der secundäre. Diese letzteren Vorgänge sind vom Anfang bis zur Vollendung zu verfolgen, wie nehmlich zunächst der Zellleib sich zu einem Saftspalt oder Vacuole umformt, wobei der Kern an der Wand liegen bleibt, dann geht der restirende Kern in die Schlummerform über, bis schliesslich die Spalten jedes Kernes entbehren. Die 
Zellen in den Spalten sind demnach als fixe Gewebszellen aufzufassen.

Ueber das Muttergewebe dieses Polypen bietet das mikroskopische Präparat wenig Anhaltspunkte. Es ist aber wohl dieses Schleimgewebe als fibröses anzusprechen da es zahlreiche Nasenpolypen giebt, die eine derbe bindegewebige Beschaffenheit haben und bei denen man mit Sicherheit nachweisen kann, dass sie ihren Ursprung aus dem submucösen Bindegewebe genommen haben. Dieses möchte ich auf den vorliegenden Fall übertragen und auch hier behaupten, dass dieses Schleimgewebe sich gebildet hat durch Umwandlung aus den Faserzügen der Submucosa, dass aber hier der Umbildungsprozess einen solchen Abschluss erhalten hat, dass sich nirgends mehr reifere bindegewebige Elemente vorfinden.

Fall 20. Fibromyxom des linken 0variums einer an Ulcus ventriculi perforatum mit nachfolgender Peritonitis gestorbenen 44 jährigen Frau.

Beide Ovarien sind in Tumoren umgewandelt, das rechte hat die Grösse einer Faust, das linke die Grösse eines Taubeneies. Es werden von dem linken Tumor Stücke in Flemming'sche Lösung gelegt, in Alkohol gehärtet.

Die Untersuchung des frischen Objectes ergiebt neben Stellen, welche eine fibrilläre Struktur haben, andere, wo sich das Bindegewebe in eine homogene Masse amgewandelt hat, in der Zellen liegen, theils zerstreut, theils zu Gruppen vereinigt, welche vielfach durch Ausläufer anastomosiren. Die Reaction mit Essigsäure liefert die ausgesprochene Mucinreaction.

An mit Saffranin gefärbten, vorher gebärteten Schnitten bestätigt die Untersuchung mit schwacher Vergrösserung die Untersuchung des frischen Objectes, indem neben Stellen mit fibrillärer Struktur sich Stellen finden, welche eine homogene Grundsubstanz haben mit Zellen in derselben, die vielfach unter einander anastomosiren.

Bei stärkster Vergrösserung fallen im Gesichtsfeld zahllose Kerne vom Typus der Endothelien auf, welche rosa gefärbt sind, ein oder mehrere Kernkörperchen besitzen und vielfach von kleinen, intensiv schwarz gefärbten Fettröpfchen, die sich meist an den Polen gruppirt haben, umlagert sind; der Zellleib ist zu langgestreckten Spindeln ausgezogen, so dass grosse Spindelzellen entstehen, welche in. Reihen angeordnet sind, und vielfach anastomosiren. Bei genauerer Betrachtung zeigt sich, dass diese Reihen von Zellen kleinsten Capillaren, in deren Wandungen sie liegen, angehören. Das auf diese Weise entstehende Kanalwerk von Capillaren durchzieht die schwach rosa gefärbte bomogene Zwischensubstanz, welche folgende Verschiedenheiten erkennen lässt. Die homogene Zwischen- 


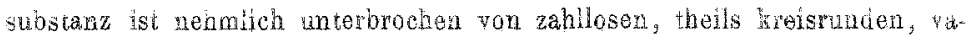
wulenähnlichen Lücken, theils feinen. Spalten, letztere sind allerdings beaeutend in der Minderzahl vorhanden. In diesen Lïcien gewahrt man wandständige Kerne rom Typus der Endothelkerne, die sowohl eine mehr wundiche, als längliche platte Gestalt haben, so dass es den Eindruck inacht, als ob die platten Kerne an die Wand gedrängt wären; in vielen Lücken fehlt jeglicher Kern, an manehen ist er sehr schwach gefärbt. Dasselbe Verhalten der Kerne trifft man bei den Spalten an. Auch direct in der Zwischensubstanz liegen vereinzelt Kerne, deren zugehöriger Zelleib nicht mekr von der umgebenden. Grundsubstanz zu trennen ist; sio sind verschieden gefärbt, machen iu der. Färbung alle Nüancen vom schönen deutlichen Roth bis zum sehwachen Rosa durch, an oinigen Stellen ist der Kern abgeblasst und erscheint als gerade noch schwach rosa gefärbter Hauch.

Epikrise: Der Prozess, der sich an dem vorliegenden Gewebe abgespielt hat, ist der, dass sich das firilläre Bindegewebe in Schleingewebe umgewandelt hat. Auch an diesem Schleimgewebe ist nachzuweisen, dass die schleimige Grundsubstanz nicht ein Abscheidungsprodukt der Zellen ist, die hier meist den Typus der Endothelzellen haben, sondern entstanden ist durch Umwandlung von Zellen; gewahrt man doch in ihr neben vollständigen Zellen freie Kerne, deren Zelleib von der mmgebenden Intercellularsubstanz nicht mehr zu trennen ist, sondern sich in diese schon umgewandelt hat, neben freien Kernen ferner in Auflösung begriffene Kerne, woraus hervorgeht, dass sowohl Zellleib wie Zellkern sich am Aufbau der Intercellularsubstanz betheiligt. Andere Zellen formen sich zu Saftspalten um, die je nachdem, ob sie längs oder quer getroffen sind, als Lücken oder Spalten erscheinen; an den Wandungen dieser Spalten erkennt man noch die Kerne der ehemaligen Zellen, wo sie nicht mehr vorhanden sind, sind sie in den Schlummerzustand ïbergegangen. Diese Spalten sind Lymphspalten, mit Lymphe gefülit, welche die $Z$ wischensubstanz in allen Richtungen durchziehen, und dem Schleimgewebe die eigenthümlich weiche sulzige Consistenz verleihen. Diese Spalten lassen beim Einschneiden des myxomatösen Gewebes ihre Elüssigkeit anstreten, wodurch das Gewebe collabirt. Eine dritte Reihe von Zellen tritt in Anastomose mit einander, das Zellprotoplasma Sormt sich zu Kanäleu um; es entstehen Capillaren, in denen man an manchen Stellen rothe Blutkörperchen erkennen kann.

Die Gewebszellen formen sich also einmal zu Grundsubstanz 
um und das ist immer das primäre, dann formen sich in dieser präformirten Grundsubstanz wieder andere Gewebszellen zu Spalten um, von denen zunächst noch nicht mit Sicherheit entschieden werden kann, ob es sich um Lymphspalten oder um Capillaren handelt (siehe Anm. S. 465). Im vorliegenden Falle sind schon einige dieser Spalten. zu Capillaren geworden, da man rothe Blutkörperchen in ihrem Lumen findet.

Die Genese dieses Schleimgewebes ist hier vollständig klar, es handelt sich um fibröses Schleimgewebe; kann man doch die Umwandlung aus den Bindegewebsfasern mikroskopisch verfolgen.

Fall 21. Myxolipom vom Oberarm einer 60jährigen Frau von Prof. Helferich exstirpirt am 21. 0ct. 1891 (Fig. 1).

Das Myxolipom, das von der hiesigen chirurgischen Klinik geschickt ist, lässt an frischen dünnen Schnitten, die mit wässriger Methylenblaulösung gefärbt sind, in sehr deutlicher Weise das Verhalten der jungen Fettzellen erkennen. Während ein Theil der grossen, deutlichen, meist ovalen, granulirten Zellen wit ovalem, bellem Kern und einem oder zwei Kernkörperchen frei von Einschlüssen ist, und ron homogener (fadenziehender) Intercellularsubstanz umgeben ist, welche von feinen verzweigten Fibrillen durchzogen wird, so enthalten andere Zellen kleine und grössere Fettropfen und stellen die verschiedenen Entwickelungsstadien der Fettzellen dar. Diese verschiedenen Zellen liegen nun in ziemlich weiten Abständen von einander, und zwischen ihnen finden sich zahlreiche Zellen, welche alle Stadien bis zum Uebergang in vollendete Schlummerzellen darstellen. Zuerst sind diese Zellen "durch Ausläufer mit den saftreichen Zellen in Anastomose; manche enthalten kleine Fetttropfen um den Kern herum. Dann wird das Zellenprotoplasma immer mehr homogen und undeutlich, man sieht aber noch einen Kern mit Kernkörperchen und Fibrillen in der Richtung, wie die Ausläufer der Zellen von diesen ausstrablen. Dann wird der Kern ganz blass, nur das Kernkörperchen zeigt noch deutlich Färbung, und die Kernmembran bildet einen schwachblauen Ring. Dann sieht man rundliche, äusserst schwach gefärbte, und nur beim Wechseln von diffusem und abgeblendetem licht noch sicher als Kerne zu erkennende Kügelchen oder ovale Körper. Dann endlich entstehen sternförmige Figuren in der sonst homogenen Intercellularsubstanz, welche aber im Knotenpunkte der Fibrillen keine Spur einer Färbung wahrnehmen lassen (ähnlich $\mathrm{F}$ und $\mathrm{K}$ Fig. 2).

Die Zahl dieser Figuren ist beträchtlich grösser als die AnzahI der saftreichen oder mit Fett gefüllten, gut färbbaren Zellen (bezw. Kerne), so dass in dem grossen, gelappten Tumor offenbar viel mehr Zellen in die Schlummerform als in reguläre Fettzellen übergehen. Einen durchgreifenden Unterschied der jungen Zellen des Myxolipoms von den darin ent- 


\section{6}

Saltenen Blutgefässzellen kanu ich -- abgesehen von der inordnung -..nicht recht feststellen, da auch manche der spindeligen Zellen der Gefässwände Fetttropfen enthalten und andererseits Fettzellen Sprossen zeigen, wie sie sonst an wachsenden Capillaren vorkommen.

Es werden nun von dem Tumor Stücke in Flemming'sche Flüssigkeit eingelegt, in Alkohol gehärtet und mit Saffranin gefärbt.

Bei der Untersuchung an gefärbten Schnitten mit schwacher Vergrösserung sieht man in einer schwach rosa gefärbten Intercellularsubstanz, die ron Kernen und zahllosen feinsten Fasern nach allen Richtungen durchzogen wird, Capillaren (Fig. $1 \mathrm{~A}$ ), an deren Wandungen man noch roth gefärbte, meist längliche Kerne erkemnen kann.

Bei Betrachtung mit stärkster Vergrösserung ergiebt sich, dass die bei sohwacher Vergrösserung erkennbaren stärkeren Fasern intensiv blauroth gefärbte elastische Fasern sind, die vielfach in ihrem Verlauf eine spindeltömige Anschwellung zeigen, die bald ganz gering ist, bald so gross wird, dass sie einen deutlieh granulirten Kern vom Typus der Gewebskerne in sich aufnimmt. Die schwächeren Fasern ergeben sich ais der Intercellularsubstanz angehörige Fasern, deren Entstehung aus den Gewebszellen man deutlich verfolgen kann. Zuerst stehen die Zellen, die oben als sternrörmige beschrieben sind und eine deutliche Differenzirung des Zellleibes znd Kernes erkennen lassen, durch lange Ausläufer in Anastomose, allmählich wird das Zellprotoplaswa undeutlich und lässt sich nicht mehr mit Sicherheit yon der umgebenden, meist homogenen Intercellularsubstanz erkennen; der Kern bleibt noch deutlich mit Kernkötperchen erkennbar, abenso sind die sternförmigen Ausläufer der Zellen als deutliche, feimste, rom Kern ansstrahlende Fibrilen erkennbar. Allmählich geht auch der Kern in den Schlummerzustand über (Fig. $1 \mathrm{~S} z$ ), er blasst ab, die Kernmembran bleibt zunächst zugleich mit dem Kernkörperchen noch erkennbar, allmählich schwindet auch diese und man sieht dann nur noch feinste fibrilläre, sternförmige Figuren (Fig. $1 \mathrm{~F}$ ) in der homogenen Intercellularsubstanz. Bei ganz genauer Betrachtung ergiebt sich, dass diese feinste fibrilläre Struktur der Grundsubstanz (Fig. 1 G) sich grösstentheils auf diese sternförmigen Figuren zurückfühen lässt, wo dies nicht möglich ist, dürfte der Zellkern in einer anderen Ebene gelegen sein.

In weit geringerer Anzahl als diese Zellen, die sich in Intercellularsubstanz ungeformt haben, ist die Zahl der Zellen, welche Fetttropfen aufgenommen haben. Man erkennt nehmlich schön gefärbte Zellen, welche sinen deutlichen Kern mit Kernkörperchen erkennen lassen und theils mit einer grossen Anzahl kleinster Fetttropfen, theils einer geringen Anzahl grosser Fetttropfen angefülli sira. Bei FZ sind Fettzellverbände abgebildet, deren Membranen Kerne im Uebergange zura Schlummerzustande enthalten.

An den Capillaren (Fig. 1 A), in denen man an zahlreichen Stellen noch rothe Blntkörperchen sieht, finden sich in der Wand vielfach längliche Kerne, um welche noch kleinste Fettropfen gelagert sind, andererseits zeigen auch viele Zellen lange Ausläufer and Sprossen (Fig. 1 B), wie 
man sie bei der Entwickelung der Capillaren beobachtet. Diese Sprossen sind theils solide Stränge, theils schon deutlich als Röhren erkennbare, doppelt contourirte Fortsätze der Zellen.

Epikrise: Es handelt sich im vorliegenden Falle um einen Tumor, in dem ein Theil der Gewebszellen sich zu Fettzellen umformt; man sieht die verschiedenen Stufen der Entwickelung solcher Zellen: zunächst Zellen, die nur eine ganz geringe Menge Fetttropfen enthalten, zwischen denen man noch deutlich das fein granulirte Protoplasma der Zelle erkennen kann, der Kern mit Kernmembran und Kernkörperchen ist rund und deutlich gefärbt. Dann folgen als nächste Stufe Zellen, wo der ganze Zellleib von feinsten Fetttropfen ganz erfüllt ist, so dass das Protoplasma undeutlich wird. Allmählich fliessen die Fetttröpfchen zusammen, der Kern wird an den Rand der Zelle gedrängt, nimmt mehr längliche Gestalt an, und eine junge Fettzelle, d. h. der Anfang zu einem Fettzellenverband ist fertig. Diese jugendlichen Fettzellen nun bilden sich offenbar zu Capillaren um; denn einmal entdeckt man an den Capillaren Kerne, welche von feinsten Fetttröpfchen umlagert sind, andererseits findet man Gewebszellen mit Sprossen, wo sich bis in die feinsten Ausläufer die Fetttropfen verfolgen lassen.

Einen anderen Gang machen die anderen und zwar der bedeutend grössere Theil der Gewebszellen darch; sie wandeln sich in Intercellularsubstanz um, und gehen in den Schlummerzustand über. Zuerst versehwindet der Zellleib, dann der Kern und schliesslich bleiben feinste sternförmige Figuren über, welche der Intercellularsubstanz ein faseriges Aussehen verleihen. Dieses faserige Aussehen der Intercellularsubstanz wird noch bedeutend erhöht durch die Umwandlung der Gewebszellen in elastische Fasern. Zunächst erkennt man in den Fasern deutlich die Gewebskerne, dann verschwinden auch diese, es bleibt eine spindelförmige Anschwellung der Faser übrig, bis auch diese verschwindet.

Es lässt sich hier von Stufe zu Stufe verfolgen, wie die Intercellularsubstanz nicht, wie Virchow annimmt, ein Abscheidungsprodukt der Zellen ist, sondern selbst aus Zellen besteht, die unter normalen Ernährungsverhältnissen nur nicht sichtbar sind, sondern sich in der Schlummerform befinden. 
Da die Zahl der sternförmigen Figuren eine weit grössere ist als die Zahl der ausgebildeten Fettzellen FZ, so lässt sich schliessen, dass weit mehr Zellen in die Schlummerform übergehen und zur Bildung der Intercellularsubstanz beitragen als sich zu Fettzellen umbilden.

Fall 22. Myxosareom yom Vorderarm. Exstipirt von Iern Prof. Helferich 22. Octobor 1891. (Fig. 3.)

Die Geschwulst entbält Abschnitte, in welchen der durchscheinende Charakter des Schleimgewebes überwiegt, und solche, welche noch das Aussehen markiger Sarcome baben. Am frischen Präparat ergeben die ersteren reichliche Mucinfällung. Mit starker Vergrösserung findet man in beiden Abschnitten grosse sternförmige oder rundliche, vielfach mit langen faserartigen Protoplasmafortsätzen versehene Zellen F, von denen eine grosse Anzabl schöne Figuren der indirecten Kerntheilung enthält (Fig. $3 \mathrm{MZ}$ ). Diese Zellen zeigen eine Anordnung entweder zu parallelen breiteren Reihen oder zu einerm Netzwerke C, dessen Maschen von zarten bläulichen Fasern gebildet werden, während innerhalb der Masche die Zelle $\mathrm{CZ}$ gelegen ist. An solchen Stellen, welche am deutlichsten eine Anordnung der Zellen in Längsreiben erkennen lassen, findet man breite Bänder MF mit börnigem, bläulichem Protoplasma gefüllt, welche vollkommen den Muskelfasern gleichen, welche einige Tage nach einer Durchscbneidung in zelliger Umwandlung ibres feinkörnig gewordenen Myosins begriffen sind. Stellenweise ist die Faser noch quergestreift oder halb hörnig, halb längsgestreift; an anderen sieht man nmitten der blauen börnigen Substanz ruhende ovale Kerne mit hellem Hof; an anderen sind mehrere Läcken in dem blauen Schlauche sichtbar, welche ruhende und in Mitose begriffene Kerne zeigen, an noch anderen Fasern sind einzelne oder zu mebreren hinter einander liegende Kerne vom Typus mebrkerniger Leukocyten vorhanden (Fig. 3 lZ), wie solche Dr. Krösing Bd. 128 Taf. XIII. Fig. 4 u. 7 abgebildet hat. Je mehr Zellen aus dem Muskelbündel entstanden sind, um so schmalere quer-oder längsgestreifte Fasern C bleiben übrig, aber auch diese letzten Reste, welche schmalen Bindegewebsbündeln gleichen, enthalten vielfach in Innern oder eng anliegend schlanke ovale endothelähnlicho $\mathrm{E}$ oder intensiv rothe kleeblattartige Leukocytenkerne L. Die vielen einander gleichen Mitosen in und ausserbalb der Fasern lassen keinen Zweifel daran, dass die grossen sternförmigen Ceschwulstzellen Z abenso directe Abkömmlinge der Muskelzellen sind, wie Krösing dies in Tig. 5 von den ähnlich aussehenden Zellen beim Heilungsvorgange bescbrieben hat. Der Tumor ist also seinem Wesen nach ein myogenes Sarcom. Der schleinige Antheil der Geschwulst scheint zum Theil aus einer directen Auflösung des erweichten Myosins in homogene Mucinmassen bervorzugeben; ein anderer Theil entsteht aber meiner Auffassung nach in derselben Weise, wie das lipogene oder neurogene Schleimgewebe, indem Zellen- und Kernsubstanz sich in homagene Grundsubstanz, $G$ umwandeln, während andere 
Zellen in die Bildung ron Fasern übergehen, und noch andere als permanente Zellgebilde übrig bleiben. Am deutlichsten sind diese Umformungen an den maschigen netzförmigen Stellen za beurtheilen, wo man innerhalb der Maschen neben schönen grossen in Karyokinese begriffenen Kernen blasse Kerngebilde oder einfacbe homogene Substanz sieht, deren Grösse zwar genau init derjenigen benachbarter Zellen übereinstimnt, deren Zellenleib und Kern aber nicht mehr zu unterscheiden ist (Fig. 3 mittlerer Abschnitt). Da man neben stark verblassten ovalen Kernen auch solche vom Leukocytentypus findet, welche obne erkennbaren Zellenleib in der homogenen Grundsubstanz liegen, so nehme ich an, dass auch diese abortiven Zellformen, die namentlich reichlich aus den letzten blauen Faserresten der Nuskelschläuche hervorgehen, an der Bildung der schleimigen Grundsubstanz betheiligt sind.

Epikrise: In diesem Falle findet ein directer Uebergang quergestreifter. Muskelfasern in Sarcomgewebe statt; letzteres macht zum Theil einen Uebergang in eine Art von Schleimgewebe durch. Das Verhaiten der Muskeln ist in diesem Falle in hohem Grade ein actives, während ich an Muskeln in der Nähe eines lipogenen Myxoms das Hervorgehen von Sohleimgewebe aus Muskelfasern als eine Phase des Zugrundegehens durch "Druckatrophie" beschrieben habe. Eingehendere Mittheilungen über diese myogenen Myxome und Myxosarcome wird Herr Prof. Grawitz an anderer Stelle folgen lassen; in seinen Präparaten finden sich ähnliche Bänder, wie die hier als MF abgebildeten Muskelfasern, aber mit noch deutlich erhaltener Querstreifung. Auch bei der Umbildung von Muskeln zu Eiter trifft man zähe, fadenziehende Mucinsubstanz oft in reichlicher Menge an. Aehnliche Bilder mag C. 0. Weber gesehen haben, als er Bd. 39 die Muskelfasern zu Eiterkörperchen und Krebszellen zerfallen liess.

\section{Fall 23 und 24. Carcinoma gelatinosum s. mucosum.}

Es ist bekannt, dass zuweilen Krebse vorkommen, deren Stroma statt aus fasrigem Bindegewebe aus Schleimgewebe besteht. Mir liegt ein typischer Fall eines solchen Carcinoma mucosum vor, bei welchem die gegen derbes Bindegewebe vorwuchernden Krebszellen ein Erwachen von Kernen und Zellen in den Fasern bewirkt haben, worauf dann aber die erwachten Zellen in eine schleimige Grundsubstanz übergegangen sind.

Ganz anders sind die Bilder von den gallertigen Stellen eines Magenkrebses, welche dem typischen Bilde des C. gelati- 
nosum mit seinen schon nit blossem Auge sichbaren Aveolar. elelern entnommen ist.

Es bandelt sich um Präparate, weiche alle aus benachbarten Theilen der Grebsigen Wuchernugen ģnonmen sind, und hauptsächlieh aus de? Miuscularis stammen. Man erkennt in den Schnitien nicbts fon carcinomasöser Infiltration, dagegen zeigte die glatte Musculatur die scbönsten Bilder des Ueberganges der glatten Muskelfasern in ein Schleimgewebe, das in seinem histologischen Bau wieder ganz rerschieden ist von den bisher beschriebenen Formen des Status mucosus. Bei schwacher Vergrösserung treten die quergatroffenen Bündel der glatten Musculatur hervor, jedes Bündel ist ron Faserzügen umgeben. Diese Bündel sind nun nicht alle gleichmässig ॠon glatten Muskelzellen ausgefüllt, sondern bald in grösseren, bald in kleineren, meist unregelmässigen Abschnitten in eine schleimige, helle, durchscheinende Substanz umgewandelt, in der sich schone grosse grauulirte Tellen befinden. Die Umwandiung der Muskelzellen, wie sich bei stärkster Vergrösserung Schritt fŭr Schritt verfolgen lässt, geschiebt nun so, dass die spindlige Muskelzelle ihre Gestalt mehr in eine runde Form ändert und stark granulirt erscheint; zunächst ist die Zelle (bei Färbung mit Saffranin und Fatfärbung in Alkohol und Pikrinsäure) noeb leicht roth gefärbt, ihr Kern tritt deutlich als ein bläschenförmiges Gebilde hervor, allnäblich wird die Zelisubstanz blasser und verliert bald ganz ihro rosarothe Färbung, bis schliesslich der Zellleib nicht mehr mit Sicherheit von der Umgebung 2 u wnterscheiden ist; es bleibt dann nur der Kern bestehen, allein aucb dieser betheiligt sich bald an der Unwandlung in die schleimige Substanz. Ist der Prozess bis zu dieser Stufe gelommen, so erkennt man dann noch die straffen, fasrigen, das Muskelbündel umgebenden Züge, von denen aus sich feinere Faserzüge durch das Bündel nach allen Ricbtungen bin vertheilen. Doch auch auf dieser Stufe macht der Prozess der Umwandlung noch nicht Halt, sondern in diesen feinen Faserzügen, welche das Muskelbündel durchziehen, erwachen Kerne, zunächst als kleine schmale, rotbe, stäbchenförmige Figuren erkennbar, welche almählich mehr Chromatin bilden, sich zu fertigen Zellen vervollständigen, welche dann dieselben Umwandlungsprozesse, wie oben geschildert, durchmachen. Wenn der Prozess der Uwawandung so weit gediehen ist, ist nichts von den feinsten Fasern webr zu sehen, sonWern die Muskelzellen in den Bündeln haben sich in eine schleimige Substanz umgewandelt; es entstehen dann Bilder, wo Alveolen mit dieser sehleimigen Substanz ganz und gar ausgefüllt sind, in der sich die umgewandelten, grob granulirten Zellen finden, die nichts mit Epithelzellen zu thun haben, sondern die umgewandelten glatten Muskelzellen darstellen.

Epikrise: Dieser Fall ist deshalb von Bedeutung, weil sich an ihm direct verfolgen lässt, dass auch die glatte Musculatur im Stande ist, in einen Status mucosus überzugehen, der nur ihr eigen ist. Dieser Auffassung widerspricht durchaus nicht der 
Umstand, dass sich auch die das Muskelbündel durchziehenden bindegewebigen Züge in dieselbe schleimige Substanz umbilden, sondern ich fasse diese feinen Bindegewebszüge, welche die Muskelbündel nach allen Richtungen durchziehen, nicht als Bindegewebe auf, sondern als den Status fibrosus der glatten Muskeln, als ein Fasergewebe, das durch die Umwandlung der glatten Muskelzellen entstanden ist. Bald ist die Umwandlung der glatten Muskeln in Gallertgewebe, wie hier, eine directe, bald entsteht zuerst Faserzustand, und erst aus diesem Schleimgewebe; die grobkörnigen Zellen sind aber keine Krebszellen, sondern oft weit von dem Krebs entfernt entstandene Muskelzellen.

\section{Schlussfolger ungen.}

1. Der schleimige oder gallertige Zustand, welchen Virchow als Schleimgewebe beschreibt, ist eine Gewebsform, bestehend aus 1) permanenten Zellen, 2) aus feinkörniger oder homogener oder fasriger Grandsubstanz von verschiedener chemischer Beschaffenheit, meistens reichlichem Gehalt an Mucin, 3) aus Saftkanälen, 4) verschieden reichlichen Capillaren.

2. Die Grundsubstanz ist kein Abscheidungsprodukt der Zellen, sondern sie ist durch Zellenumwandlung derart entstanden, dass ein Theil der Zellen in homogene oder körnige, ein anderer in fasrige, reticuläre Substanz übergeht; aus diesem Schlummerzustande können die Zellen wahrscheinlich wieder erwachen.

3. Die Saftkanälchen und Capillaren gehen gleichfalls aus

1) v. Recklinghausen erklärt sich die Bildung der schleimigen Substanz in den Gallertkrebsen so, dass ,bei fortschreitendem Wachsthum die epithelialen Stränge und Zapfen das Bindegewebe, in welches sie eingesetzt sind, immer mehr eingezwängt wird, schliesslich seine Faserung verliert, durchscheinend und weich, zuletzt sogar flüssig wird und bei dieser Metamorphose die Struktur des richtigen Schleimgewebes annimmt. Die Umwandlung des Bindegewebes wird wohl durch die Veränderung seines Saftstromes veranlasst, welche hauptsächlich eine Folge der Compression seitens der epitbelialen Massen ist, aber die evidenten Merkmale einer schleimigen Metamorphose besitzt". Dieser Darstellung wage ich nicht $\mathrm{zu}$ widersprechen, da sicherlich mehrere Vorgänge ganz verschiedener Art zur Bildung gallertiger Substanzen in Krebsen führen können, von denen die directe schleimige Metamorphose der Muscularis nur ein Beispiel liefert. 
Zellen hervor, die Saftkanälchen exchalten anfanglich Kerne, später können diese in den Schlummerzustand übergehen, so dass kernlose Röhren entstehen, in welchen Iymphe fliesst. Bei reichlichem Gehalt an Lymphe kann das Bild von ödematösem Bindegewebe vorgetäuscht werden.

4. Rein histologisch ist Tela mucosa als Gewebsgruppe mit vielen Spielarten zu trenuen von T'ola fibrosa, adiposa, cartilaginea, ossea, von Tela muscularis und Tela nervosa.

5. In der systematischen Stellung nimmt aber das sogenanate Schleimgewebe einen gesonderten Platz ein, da es in seinem fertigen Organ als definitives Gewebe vorkommt, sondern nur den Rang einer Modification, eines Status mucosus besitzt, wie etwa das Knochenmark im Status fibrosus vorkommen kann, ohne deshalb definitive Tela fibrosa za sein: in dieser Hinsicht ist es also von den anderen Geweben nicht za trennen.

6. Schleimgewebe ist weder morphologisch noch histogenetisch eine Einheit, sondern alle Gewebe der Bindesubstanzen, sowie Muskel- and Nervengewebe können in ein glasiges, gallertiges, häufig mucinhaltiges Stadium übergehen. Jedes definitive Gewebe besitzt also einen ihm allein zukommenden Status mucosus. Innerhalb der einzelnen Gewebsarten kommen Varietäten vor, z. B. der Status mucosus des Fettgewebes Jeim Embryo ist verschieden von dem Status mucosus des senilen Fettgewebes oder demjenigen eines Lipomyxoms.

7. Muskelfasern und Nerven können entweder direct in den Status mucosus umgewandelt werden, oder sie können zuerst in Status fibrosus oder adiposus übergehen, und dann secundär die Struktur der Tela mucosa annehmen. Die Umwandlung in Faserbündel macht aber aus dem Muskelgewebe keine definitive Tela sbrosa, denn der Status fibrosus kann wieder zur früheren Ausbildung der contractilen Fasern zurückkehren; eben so wenig macht die Umbildung eines glatten Muskelbiindels in den Statos mucosus (Gallertkrebs) oder die Umbildung eines peripherischen Nerven in den Status mucosus (Rankenneurom) aus diesen Muskeln oder Nerven das Schleimgewebe, also die Vorstufe des Fettgewebes, sondern eine besondere Unterart von Gewebe mit schleimiger Grundsubstanz. 